\title{
Corrected and Republished from: "A Novel, Multiple-Antigen Pneumococcal Vaccine Protects against Lethal Streptococcus pneumoniae Challenge"
}

\author{
Win-Yan Chan, ${ }^{\text {a* }}$ Claire Entwisle, ${ }^{\mathrm{b}}$ Giuseppe Ercoli, ${ }^{a}$ Elise Ramos-Sevillano, ${ }^{\mathrm{a}}$ Ann Mcllgorm, ${ }^{\mathrm{b}}$ Paola Cecchini, ${ }^{\mathrm{b}}$ Christopher Bailey, ${ }^{\mathrm{b}}$ \\ Oliver Lam, ${ }^{\mathrm{c}}$ Gail Whiting, ${ }^{\mathrm{c}}$ Nicola Green, ${ }^{\mathrm{d}}$ David Goldblatt, ${ }^{\mathrm{d}}$ Jun X. Wheeler, ${ }^{\mathrm{c}}$ Jeremy S. Brown ${ }^{\mathrm{a}}$
}

aCentre for Inflammation and Tissue Repair, UCL Respiratory, Division of Medicine, University College Medical School Rayne Institute, London, United Kingdom

blmmunoBiology Ltd., Babraham, Cambridge, United Kingdom

cNational Institute for Biological Standards and Control, South Mimms, Potters Bar, Hertfordshire, United Kingdom

dUCL Great Ormond Street Institute of Child Health, London, United Kingdom

ABSTRACT Current vaccination against Streptococcus pneumoniae uses vaccines based on capsular polysaccharides from selected serotypes and has led to nonvaccine serotype replacement disease. We have investigated an alternative serotype-independent approach, using multiple-antigen vaccines (MAV) prepared from S. pneumoniae TIGR4 lysates enriched for surface proteins by a chromatography step after culture under conditions that induce expression of heat shock proteins ( $\mathrm{Hsp}$; thought to be immune adjuvants). Proteomics and immunoblot analyses demonstrated that, compared to standard bacterial lysates, MAV was enriched with Hsps and contained several recognized protective protein antigens, including pneumococcal surface protein A (PspA) and pneumolysin (Ply). Vaccination of rodents with MAV induced robust antibody responses to multiple serotypes, including nonpneumococcal conjugate vaccine serotypes. Homologous and heterologous strains of S. pneumoniae were opsonized after incubation in sera from vaccinated rodents. In mouse models, active vaccination with MAV significantly protected against pneumonia, while passive transfer of rabbit serum from MAV-vaccinated rabbits significantly protected against sepsis caused by both homologous and heterologous S. pneumoniae strains. Comparison of MAV preparations showed that culture at $30^{\circ} \mathrm{C}$ and then switching to $37^{\circ} \mathrm{C}$ had limited effects on antigenicity compared to culture at $37^{\circ} \mathrm{C}$ throughout. Overall, these data suggest that the MAV approach may provide serotype-independent protection against S. pneumoniae.

KEYWORDS Streptococcus pneumoniae, multiple-antigen vaccine, protein antigen, vaccines

\section{INTRODUCTION}

treptococcus pneumoniae is a common cause of community-acquired pneumonia (CAP), septicemia, and meningitis (1), as well as of noninvasive diseases, such as acute otitis media (AOM) and bronchitis (2). Over 90 different serotypes of S. pneumoniae, determined by the characteristics of the capsular polysaccharide (CPS), have been identified (3). There are currently two vaccines available to prevent S. pneumoniae infections: the pneumococcal polysaccharide vaccine (PPV) and the pneumococcal conjugate vaccine (PCV). Each consists of capsular polysaccharide antigen from a limited panel of S. pneumoniae serotypes. In the United Kingdom, PPV remains the first choice for adult vaccination (4), and PCV is routinely included in childhood immunization schedules worldwide, as it has greater efficacy than PPV in infants. Unfortunately, in developing countries the high cost of PCV restricts its availability, and in addition, serotype coverage is reduced, as PCV was designed to include the most prevalent serotypes in North America (5). Furthermore, serotype replacement in response to PCV vaccination

Citation Chan W-Y, Entwisle C, Ercoli G, RamosSevillano E, Mcllgorm A, Cecchini P, Bailey C, Lam O, Whiting G, Green N, Goldblatt D, Wheeler JX, Brown JS. 2022. Corrected and Republished from: "A novel, multiple-antigen pneumococcal vaccine protects against lethal Streptococcus pneumoniae challenge." Infect Immun 90:e00846-18a. https:// doi.org/10.1128/Al.00846-18a.

Editor Liise-anne Pirofski, Albert Einstein College of Medicine

Copyright $\odot 2022$ Chan et al. This is an openaccess article distributed under the terms of the Creative Commons Attribution 4.0 International license.

Address correspondence to Jeremy S. Brown, jeremy.brown@ucl.ac.uk.

*Present address: Win-Yan Chan, UCB, Slough, United Kingdom.

Received 28 November 2018 Accepted 29 November 2018

Accepted manuscript posted online

12 January 2022

Published 25 January 2022 
alters the ecology of $S$. pneumoniae, reducing the efficacy of polysaccharide vaccines over time (6). A vaccine based on protein antigens may provide a low-cost alternative approach capable of inducing cross-serotype protection $(7,8)$.

One vaccine approach dependent on protein antigens is a whole-cell approach, a cost-effective method of immunizing with a large number of potential protein antigens to potentially induce serotype-independent protective immunity. In addition, a wholecell approach could target both humoral and cellular host immunity $(9,10)$, potentially enabling clearance of both disease and colonization. Several groups have therefore studied a whole-cell vaccine approach against $S$. pneumoniae, including progression to early-phase clinical trials (11-13). An alternative to maintaining protein antigens as part of the whole $S$. pneumoniae bacterium is using a bacterial lysate as a vaccine, which could result in a more stable preparation that is better suited to vaccine delivery than a whole bacterium. However, the antigenicity of whole-cell lysates may be weak and require enhancement (14). One method of enhancing immunogenicity is altering the preparation of the lysate to ensure increased representation of immunoprotective proteins. This can be partially achieved using anion-exchange chromatography with a pH 8.0 buffer to preferentially capture several well-known S. pneumoniae antigens, all of which have a pl of 7.5 or lower, including PiuA, PiaA, PsaA, RrgA, RrgB, ClpP, PspA, and Ply. In addition, growth under stress conditions, such as high temperatures, to induce heat shock proteins (Hsps) could increase antigenicity (15), as Hsps facilitate the cross-presentation of peptides $(16,17)$ and act as natural adjuvants by stimulating macrophages and dendritic cells to cause cytokine secretion (18-20). As a result, Hsps have been studied as vaccines that protect against cancer as well as microbial pathogens (21), with a number of bacterial Hsps showing promise as vaccine candidates (22-24), including in models of lethal lung infection (25-27). For example, mice intranasally immunized with the S. pneumoniae Hsp DnaJ (Hsp40) or Hsp caseinolytic protease $\mathrm{P}(\mathrm{ClpP})$ were protected from S. pneumoniae infection, including against systemic challenge with a panel of heterologous strains (28). Hence, Hsps are potential vaccine antigens with advantageous immunomodulatory properties that could be used as a component of a broadly protective $S$. pneumoniae vaccine.

Here we present data on a multiple-antigen approach to a novel S. pneumoniae vaccine based on bacterial lysates that combines the advantages of a whole-cell approach with the potential additional benefit of an increased Hsp and surface antigen content in the vaccine preparation.

\section{RESULTS}

Formulation of an S. pneumoniae MAV. A multiple-antigen Hsp-enriched preparation based on a whole-cell preparation was formulated using the ImmunoBiology Ltd. platform technology as previously described (29). Heat shock was used to enrich for Hsps, and anion-exchange chromatography was used to enrich for negatively charged S. pneumoniae antigens (e.g., PspA and Ply) (Fig. 1A). Immunoblots determined which elution fractions contained the highest concentration of the Hsp60 and Hsp70 proteins and demonstrated a marked increase in the expression of both the Hsp60 and Hsp70 content in the multiple-antigen vaccine (heat shock) (MAVhs) compared to the bacterial heat-killed lysate (HKL) (Fig. 1B and C). A pooled human IgG preparation known to recognize multiple S. pneumoniae protein antigens (9) was used to probe MAVhs and HKL to determine whether there were differences in their non-Hsp contents. This demonstrated variations in the number, intensity, and molecular weights of bands identified after incubation in sera from MAVhs - or HKL-vaccinated animals (Fig. 1D). Ply activity in the MAVhs, the HKL, and a heat-killed whole-cell (HKWC) preparation formulated with the wild-type TIGR4 strain was assessed using a hemolysis assay. HKWC and HKL did not cause the lysis of red blood cells, probably due to the degradation of Ply during the heat-killing step, whereas MAVhs caused red cell lysis, suggesting that the MAVhs preparation still contained active Ply (Fig. 1E).

Proteomic analysis of MAVhs preparations. Tandem mass spectrometry (MS/MS) sequencing was used to identify proteins in the MAVhs and HKL preparations, with 
A

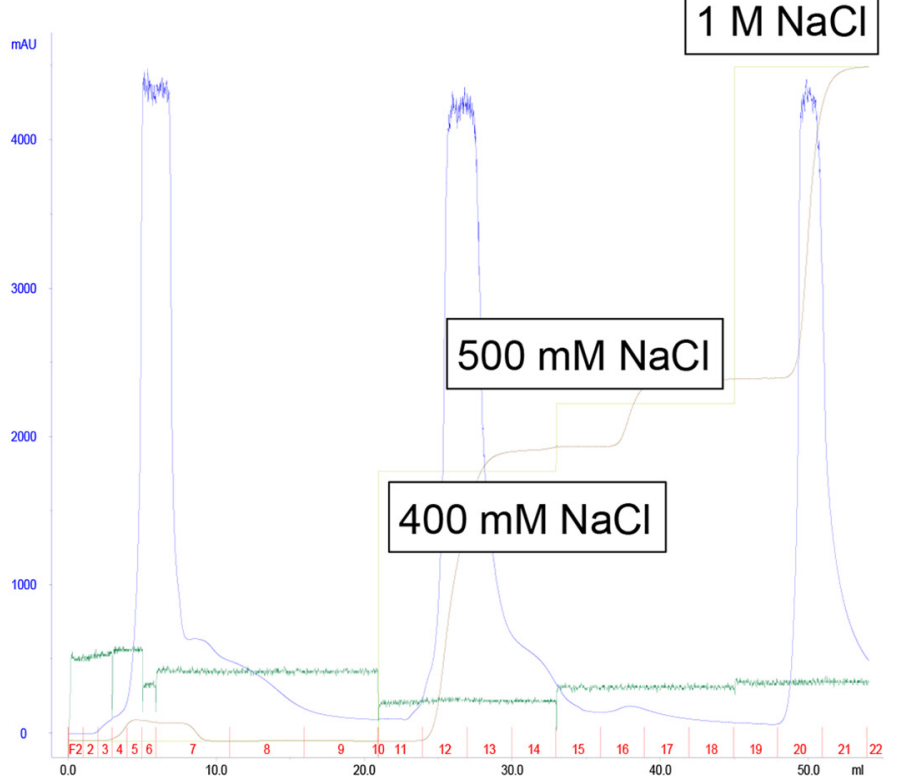

C

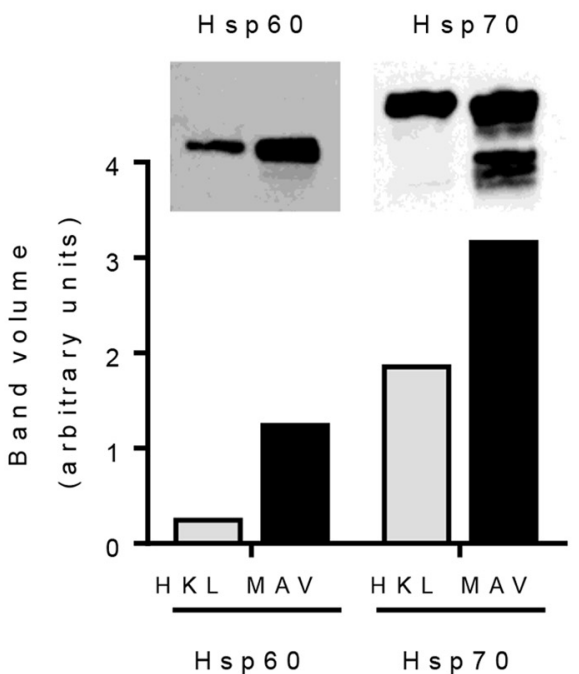

D

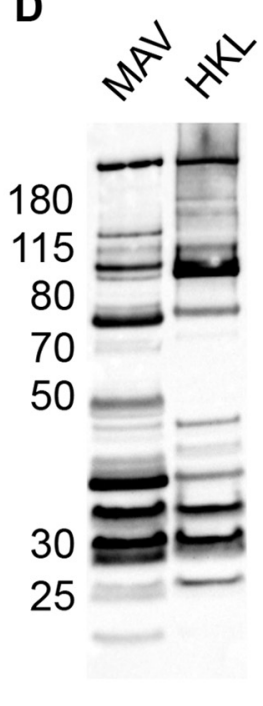

B

\section{Selected fractions}

\section{$12 \quad 13 \quad 14 \quad 15$}

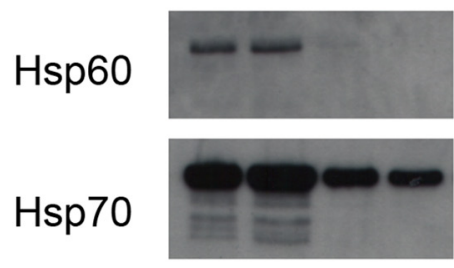

\begin{tabular}{|c|c|}
\hline Fraction & $\begin{array}{c}\text { Concentration } \\
(\mathrm{mg} / \mathrm{ml})\end{array}$ \\
\hline 12 & 0.84 \\
\hline 13 & 0.88 \\
\hline 14 & 0.25 \\
\hline 15 & 0.15 \\
\hline
\end{tabular}

E

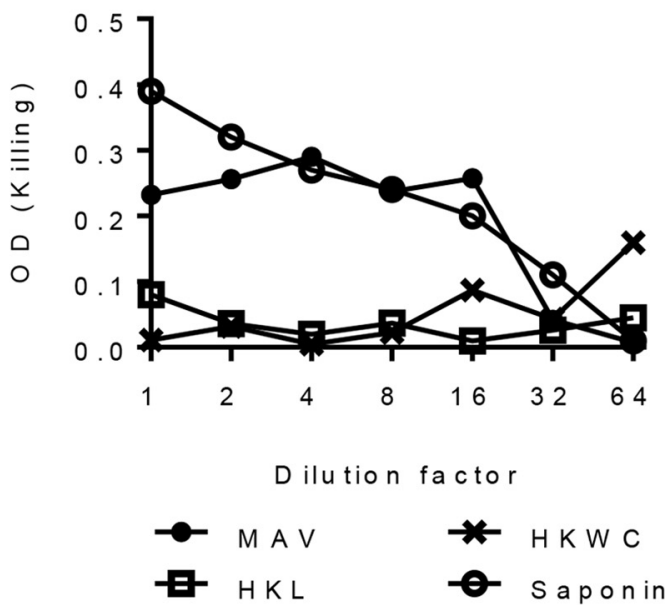

FIG 1 Formulation of a multiple-antigen S. pneumoniae TIGR4-derived vaccine preparation (MAV). (A) lon-exchange (IEX) chromatogram showing the purification of the MAV. Light green line, NaCl elution concentration; brown line, the resulting conductivity in the system; blue line, UV trace showing the concentrations of the eluted proteins (milli-absorbance units); dark green line, pressure in the system. The fractions collected are numbered in red; the total volume (in milliliters) is recorded on the $x$ axis. (B) Detection of Hsp60 and Hsp70 by Western blotting in selected ion-exchange chromatography fractions; the BCA assay protein concentrations for these fractions are shown in the table. (C) A comparison of the heat shock protein content (Hsp60 and Hsp70) measured by immunoblotting of heat-killed lysate (HKL) and MAV. The bar chart shows the pixel intensity quantification (ImageQuant TL; GE Lifesciences) for Hsp60 and Hsp70 bands. (D) Immunoblots of $5 \mu \mathrm{g}$ of total protein of either MAV or HKL probed with pooled human IgG at 1:20,000 (Pentaglobin; Paviour Pharmaceuticals, New Delhi, India). (E) Comparison of the hemolytic activity against horse red blood cells in serial 2-fold dilutions of MAV from neat to 1:64 and HKL and HKWC preparations with a saponin positive control.

tandem mass tag (TMT) labeling being used to assess relative protein quantities. A total of 627 proteins were identified and compared between the MAVhs and HKL preparations. Of these, 57 were increased $>2$-fold in MAVhs compared to HKL (see Table S1 in the supplemental material), including several Hsps and important known surface antigens, such as PavB and several lipoproteins, including PsaA, PiaA, and the Th17 antigens SP_0148 and SP_2108 (30) (Table 1). Conversely, 152 proteins were decreased by more than 2 -fold by the vaccine preparation process, including multiple proteins required for basic metabolic functions (e.g., ribosomal proteins) and capsule synthesis, but also the virulence factors and protective antigens Ply, PspA, and PspC (Table S2). 
TABLE 1 Selected proteins that TMT-MS/MS analysis shows have increased expression in the MAV TIGR4.1 preparation compared to the TIGR4 HKL preparation ${ }^{a}$

\begin{tabular}{llc}
\hline SP no. & Protein & Fold change \\
\hline Heat shock proteins & & Reference(s) \\
SP_0338 & Putative ATP-dependent Clp protease, ATP binding & 2.67 \\
SP_0517 & Chaperone protein (DnaK) & 4.33 \\
SP_0516 & Protein GrpE (GrpE) & 3.03 \\
SP_0519 & Chaperone protein (DnaJ) & 2.37 \\
SP_1906 & 60-kDa chaperonin (GroL) & 2.95 \\
SP_1907 & 10-kDa chaperonin (GroS) & 3.56 \\
Known immunogens & & 62,63 \\
SP_0082 & Cell wall surface anchor family protein (PavB) & 64,65 \\
SP_0148 & ABC transporter, substrate-binding protein & 68 \\
SP_0149 & ABC transporter substrate-binding protein (MetQ) & 5.33 \\
SP_0629 & L,D-carboxypeptidase (DacB) & 3.10 \\
SP_0845 & Nucleoside ABC transporter protein & 2.52 \\
SP_1032 & Iron compound ABC transporter (PiaA) & 3.94 \\
SP_1650 & Manganese ABC transporter lipoprotein (PsaA) & 2.37 \\
SP_2093 & Putative uncharacterized membrane protein & 2.22 \\
SP_2108 & Maltose/maltodextrin-binding protein (MalX) & 7.03 \\
\hline
\end{tabular}

aOnly proteins with an increased fold change of 2 and above are shown.

Previously, we have published data obtained using deltaDOT capillary gel electrophoresis (CGE) demonstrating a consistent protein content between different batches of MAVhs preparations (29).

Vaccination with MAV induces functional antibodies. To assess the immunogenicity of MAVhs, mice were immunized by subcutaneous injection with either MAVhs, HKL, HKWC, or the negative-control buffer using a two-dose schedule 21 days apart. Whole-cell enzyme-linked immunosorbent assays (ELISAs) demonstrated that pooled serum obtained 1 week after the second vaccinaton with MAVhs contained antibody responses to the S. pneumoniae TIGR4 strain markedly higher than those detected in serum from HKL-vaccinated mice. No statistically significant anti-TIGR4 response was identified in sera from mice vaccinated with HKWC (Fig. 2A). The serum antibody response to $M A V^{\text {hs }}$ was dominated by $\lg G$, with no significant lgM response compared to that in buffer-vaccinated mice (Fig. 2B). Significantly increased levels of anti-TIGR4

A

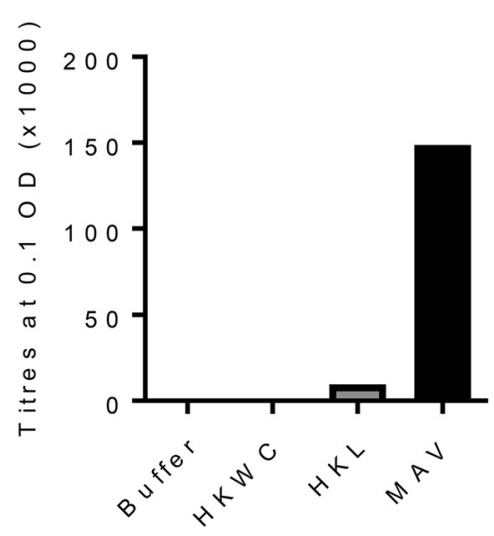

B

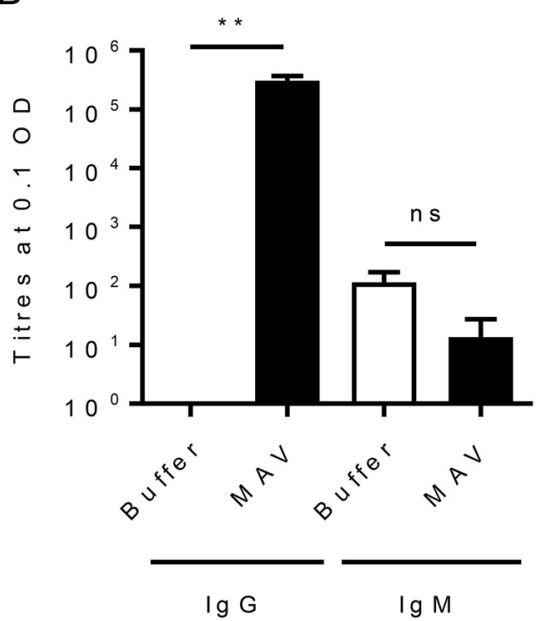

C

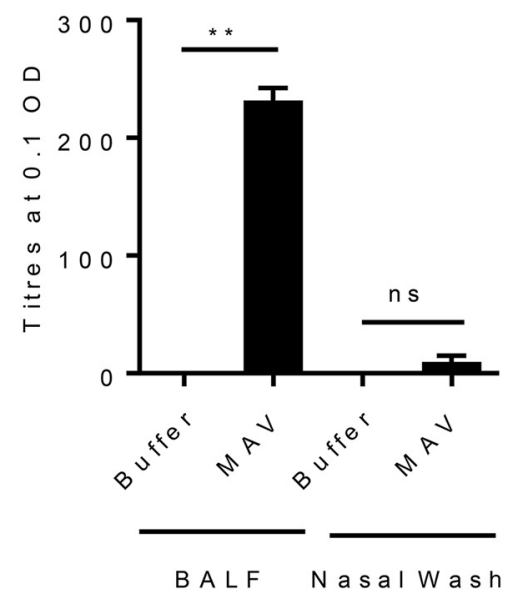

FIG 2 MAV is immunogenic in a mouse model of subcutaneous vaccination. CD1 mice were vaccinated subcutaneously with $75 \mu \mathrm{g}$ on day 0 and day 21 and culled at 28 days to obtain serum. (A) Results of a whole-cell IgG ELISA against S. pneumoniae TIGR4 for pooled sera harvested from tail vein bleeds (10 $\mu$ l per mouse, $n=6$ ). (B and C) Results of whole-cell IgG and IgM ELISAs against $S$. pneumoniae TIGR4 for pooled sera from MAV-vaccinated mice $(n=5)$ (B) and against S. pneumoniae TIGR4 for pooled BALF and nasal wash specimens from MAVvaccinated mice (C). Data are presented as the mean and $95 \%$ confidence interval. $P$ values were calculated using the Mann-Whitney $t$ test. **, $P<0.01 ; \mathrm{ns}$, not significant. 
IgG were also detected in the bronchoalveolar lavage fluid (BALF) of mice immunized with MAVhs but not in nasal washes (Fig. 2C). Whether the serum IgG induced by the MAVhs, HKL, and HKWC preparations can recognize and bind to the surface of live $S$. pneumoniae was assessed using a flow cytometry assay that correlates with protection (31). Compatible with the ELISA data, there were higher levels of IgG binding when $S$. pneumoniae TIGR4 was incubated in serum from mice vaccinated with MAVhs than after incubation in serum from mice vaccinated with HKL or HKWC. Incubation in serum from HKWC-vaccinated mice also resulted in less IgG binding to $S$. pneumoniae than incubation in sera from HKL-vaccinated mice (Fig. 3A to C). To investigate IgG binding to heterologous strains, the IgG binding assays were repeated using $S$. pneumoniae serotype 18C, 23F, 3, and 19F (EF3030) strains. Sera from MAVhs-vaccinated mice significantly increased serum IgG binding to the serotype 18C, 23F, 3, and 19F (EF3030) strains compared to that in a buffer-vaccinated control serum (Fig. 3D and E).

Sera from MAVhs-vaccinated mice bind to multiple protein antigens. Immunoblots against lysates from the S. pneumoniae TIGR4, D39, and 19A strains demonstrated that antibodies in sera from MAVhs- and HKL-vaccinated mice recognized a number of proteins which were largely conserved between the three strains. The antigens recognized after probing with sera from MAVhs- and HKL-vaccinated mice overlapped, although a band at approximately $75 \mathrm{kDa}$ (potentially consisting of multiple proteins) was recognized by serum from MAVhs-vaccinated mice but was not recognized by serum from HKL-vaccinated mice (Fig. 4A). A Meso Scale Discovery (MSD) multiplex assay that measures the levels of IgG to a panel of known S. pneumoniae surface and immunogenic proteins was used to identify some of the protein antigens recognized by sera from vaccinated mice (32). IgG in serum from a MAVhs-vaccinated mouse recognized all the antigens included in the MSD assay panel of proteins, including PspC (CbpA), PspA, PsaA, PiaA, PiuA, and the pilus proteins RrgA and RrgB, all of which have previously been shown to be protective vaccine candidates in mice (33-36) (Fig. 4B). In contrast, IgG in sera from HKL-vaccinated mice recognized fewer proteins, with no responses to PspC, LytC, PcsB, PiaA, PiuA, family 1 PspA, SP_0609, SP_2027, Spr0057 (StrH), and StkP.

Comparison of MAV preparations made under different conditions using Plydeficient S. pneumoniae. During the development of the bioreactor process, for consistency culture conditions were changed to a temperature of $30^{\circ} \mathrm{C}$ with a switch to $37^{\circ} \mathrm{C}$ for the final $30 \mathrm{~min}$. In addition to eliminating potential adverse effects caused by an active Ply, MAV preparations were made using a mutated TIGR4 strain expressing a detoxified Ply (49). To ensure culture at $30^{\circ} \mathrm{C}$ rather than $37^{\circ} \mathrm{C}$ did not alter MAV preparation antigen content significantly, two new MAV preparations termed MAVIPS004 and MAVIPS005 were prepared. MAVIPS004 was cultured at $30^{\circ} \mathrm{C}$ before switching to $37^{\circ} \mathrm{C}$ for $30 \mathrm{~min}$, and MAVIPS005 was cultured at $37^{\circ} \mathrm{C}$ throughout. Comparing the MAVIPS004 and MAVIPS005 preparations using immunoblots showed no clear differences in expression of the Hsps Hsp70 and Hsp60 or in the expression of the immunogenic proteins PspA and Ply (Fig. 5A). The capillary gel electrophoresis profiles of both preparations suggested only minor overall differences in their protein constituents (Fig. 5B). Both preparations were used to generate antisera using vaccination experiments in mice conducted at Churchill Applied Biotechnology Ltd. Sera recovered from mice vaccinated with MAVIPS004 and MAVIPSO05 showed no major statistically significant differences in flow cytometry assays of IgG binding to live S. pneumoniae bacteria or whole-cell ELISA titers against the TIGR4 S. pneumoniae strain (Fig. 5C). Specific protein antigen ELISAs demonstrated increased antibody titers to Ply in serum from mice vaccinated with heat-shocked MAVIPS004 compared to those in serum from mice vaccinated with MAVIPS005 (Fig. 5D) and reduced titers to PspA (Fig. 5E). When measured using the MSD multiplex assay (32), there were no differences between the MAVIPS004 and MAVIPS005 preparations in responses to other antigens (PiuA, PsaA, RrgA, and RrgB; data not shown). These data indicate that reducing culture temperature for the preparation of MAV to $30^{\circ} \mathrm{C}$ had limited effects on protein content or overall antigenicity. 
A

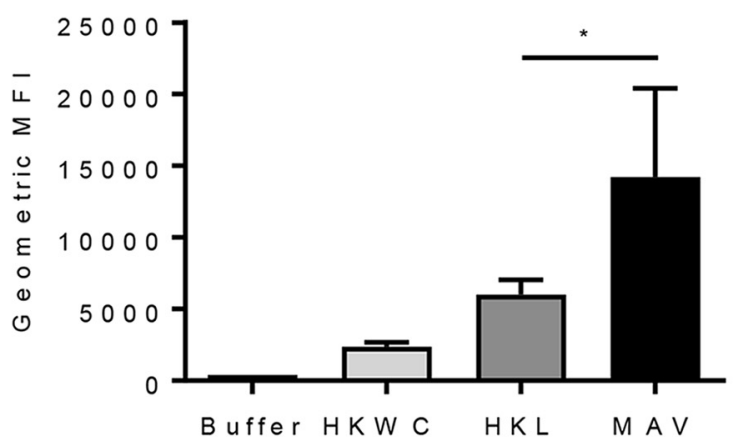

C

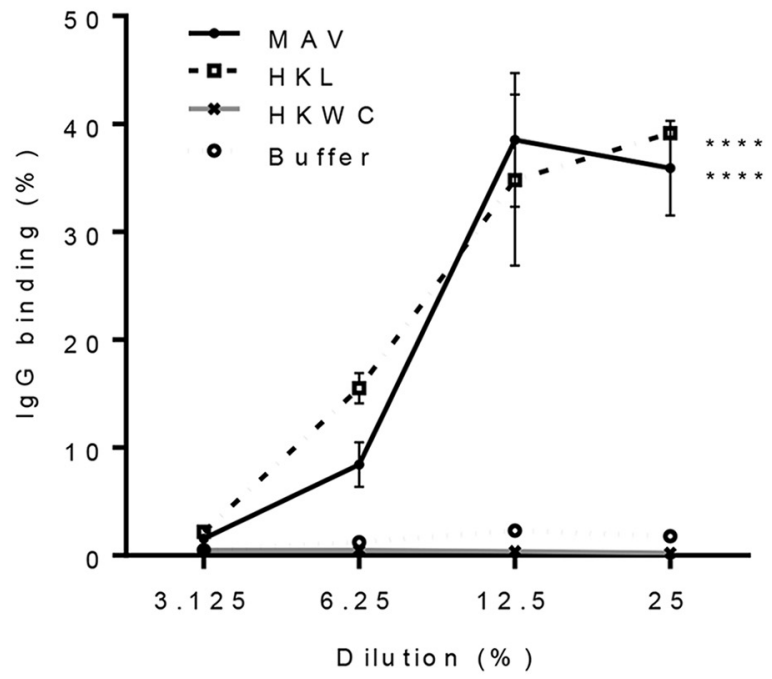

B

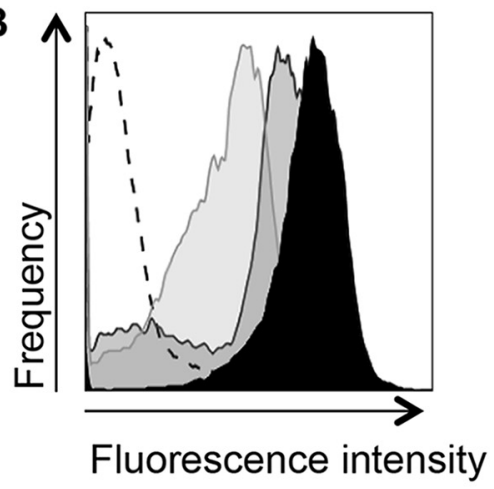

D

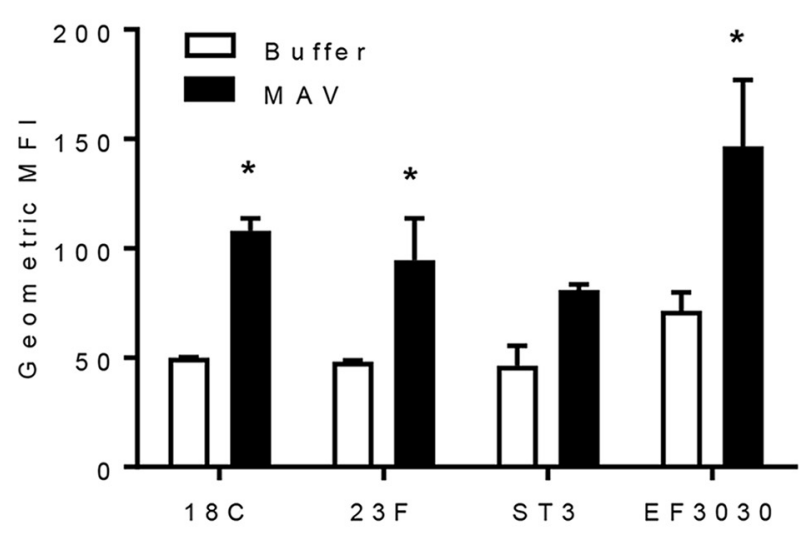

E

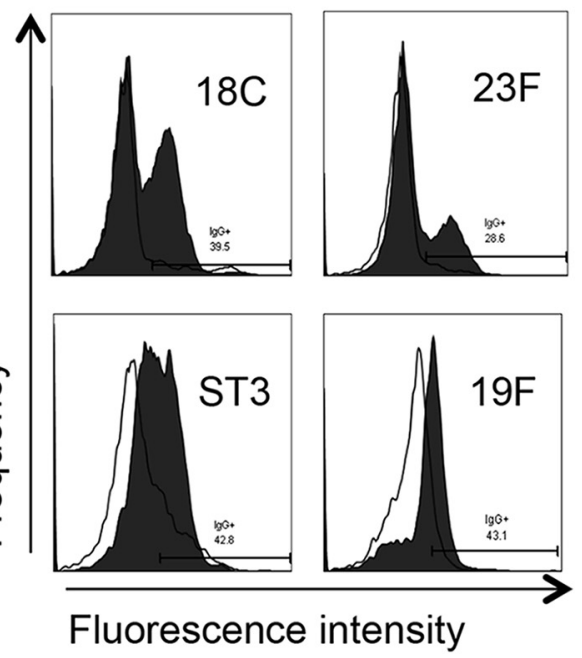

FIG 3 Binding of immune mouse sera to the surface of S. pneumoniae strains. (A) The results of IgG surface binding assays of S. pneumoniae TIGR4 incubated in sera from vaccinated mice are shown as the geometric mean fluorescence index (MFI). Error bars represent the SD from technical replicates. Significance is calculated with the Holm-Sidak test. ${ }^{*}, P<0.05$. (B) Representative flow cytometry histograms showing IgG-positive S. pneumoniae TIGR4 populations. White histogram, buffer negative-control serum; black histogram, serum from MAV-vaccinated mice; dark gray histogram, serum from HKL-vaccinated mice; light gray histogram, serum from HKWC-vaccinated mice. (C) IgG binding to TIGR4 in immune serum diluted to $25,12.5,6.25$, and 3.125\%. Data points are means from technical replicates; error bars represent standard deviations. Significance values between each dilution curve were calculated by using a two-way ANOVA and comparison to the buffer negative control. ${ }^{* * * *}, P<0.001$. (D) Mean fluorescent IgG surface binding to S. pneumoniae serotype 18C, 23F, ST3, and 19F strains incubated in sera from MAV- or buffer-vaccinated mice. Error bars represent standard deviations from technical replicates. Significance was calculated with the Holm-Sidak test. ${ }^{*}, P<0.05$. (E) Representative histograms showing a shift in populations positive for lgG against different strains of S. pneumoniae. White histogram, IgG binding in buffer-vaccinated mouse serum; shaded histogram, binding in MAV-vaccinated mouse serum. 
A
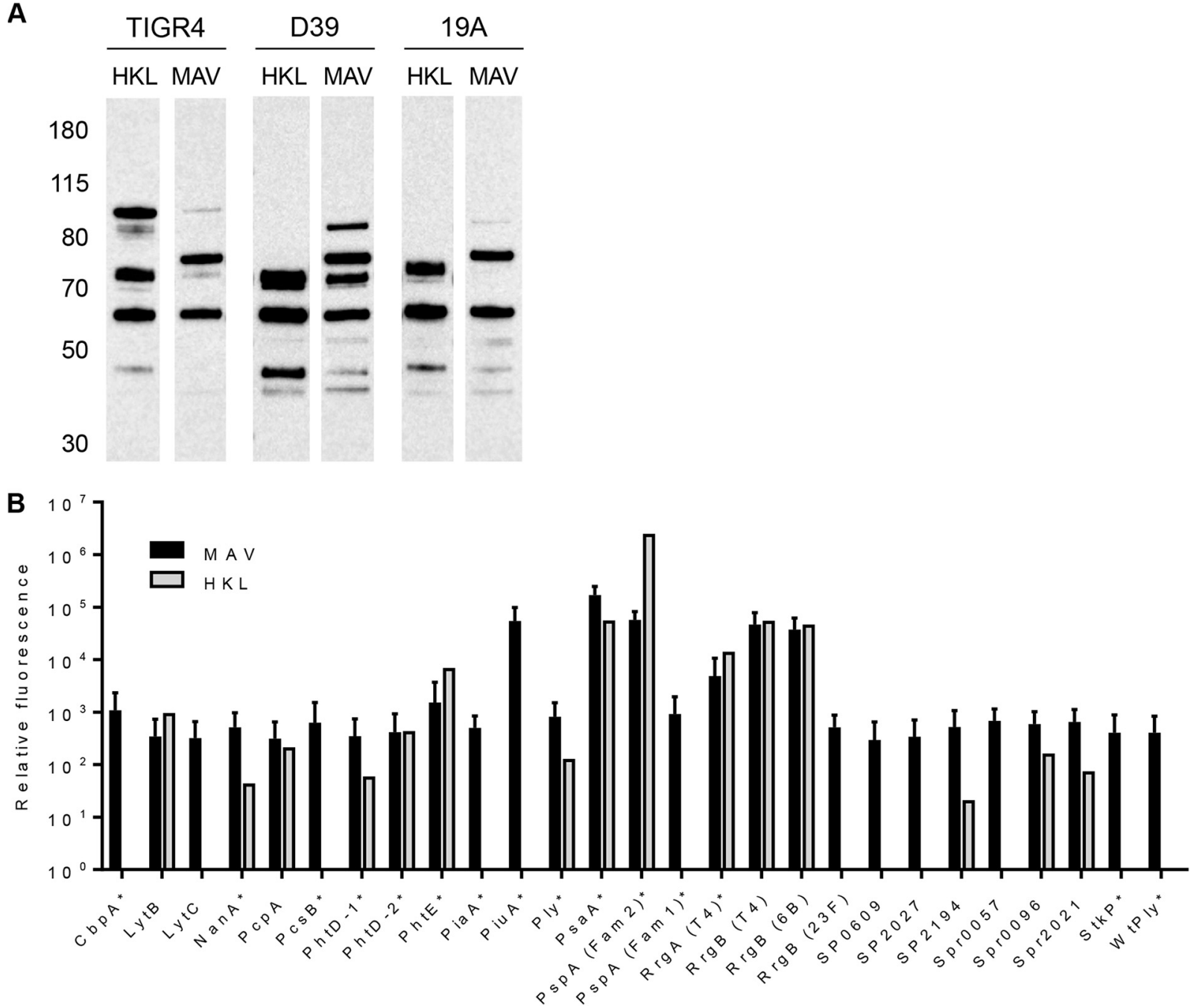

FIG 4 Identification of protein antigens recognized by sera from vaccinated mice. (A) Immunoblots of S. pneumoniae TIGR4, D39, or 19A strain whole-cell lysates probed with serum diluted 1:1,000 from mice vaccinated with either HKL or MAV. The numbers on the left are molecular masses (in kilodaltons). (B) Identification of protein antigens recognized by sera from vaccinated mice using the MSD assay. Values are normalized to those for the negative control consisting of buffer-vaccinated mouse serum. Mean values are shown, with error bars representing standard deviations for sera from mice vaccinated with MAV ( $n=3$, black columns) and a mouse vaccinated with HKL ( $n=1$, gray columns).

Protective efficacy of vaccination of mice with MAV TIGR4 preparations. Mouse models were used to determine if vaccination with Hsp-induced MAV resulted in protective immunity against $S$. pneumoniae. At $24 \mathrm{~h}$ after challenge using the pneumonia model, mice vaccinated with $M A V^{\text {hs }}$ had at least $1 \log _{10}$ fewer numbers of bacterial CFU in both the blood and lungs compared to the buffer-vaccinated controls (Fig. 6A and $B$ ). In contrast, MAVhs vaccination did not reduce the density of the number of bacterial CFU in nasal washes obtained 2 weeks after inoculation in a model of S. pneumoniae nasopharyngeal colonization with TIGR4 (Fig. 6C). In order to eliminate potential adverse effects caused by an active Ply, new MAV preparations, termed MAVIPS004 and MAVIPS014, denoting different batches, were prepared using a mutated TIGR4 strain expressing a detoxified Ply (37). Both MAVIPS004 and MAVIPS014 contained similar levels of detoxified Ply, as measured by ELISA, that stimulated an antibody response that recognized native Ply (29) and the absence of hemolysis in a red blood cell assay. Sera obtained from rabbits vaccinated subcutaneously on days 0,21 , and 35 with $375 \mu \mathrm{g}$ of MAVIPS004, the S. pneumoniae vaccine Prevenar as a positive control, or buffer were used for passive immunization of mice, followed by intraperitoneal challenge with 
A MAV HS MAV NHS
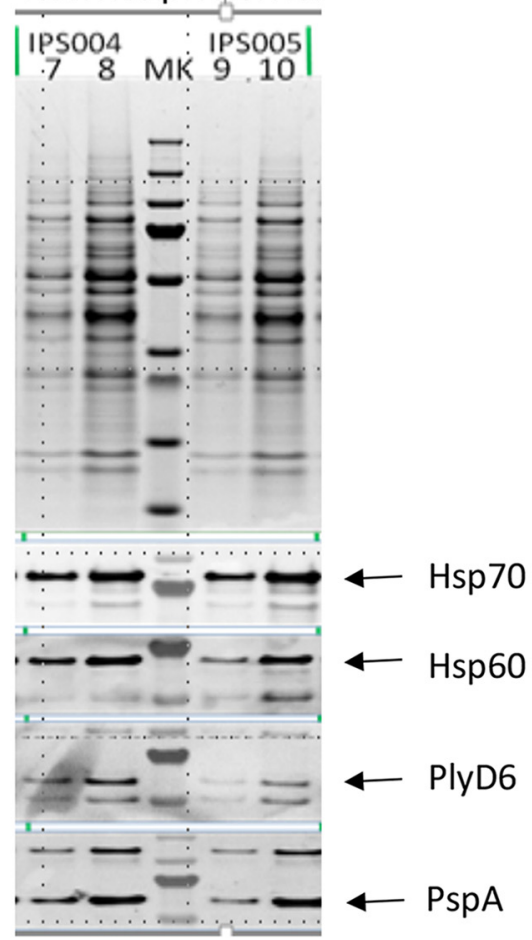

C

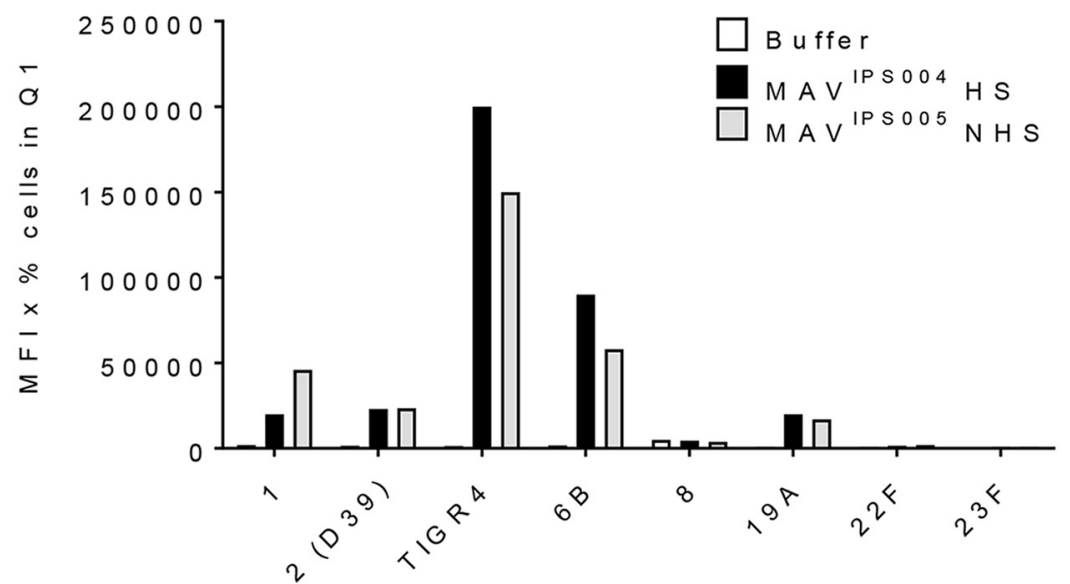

B
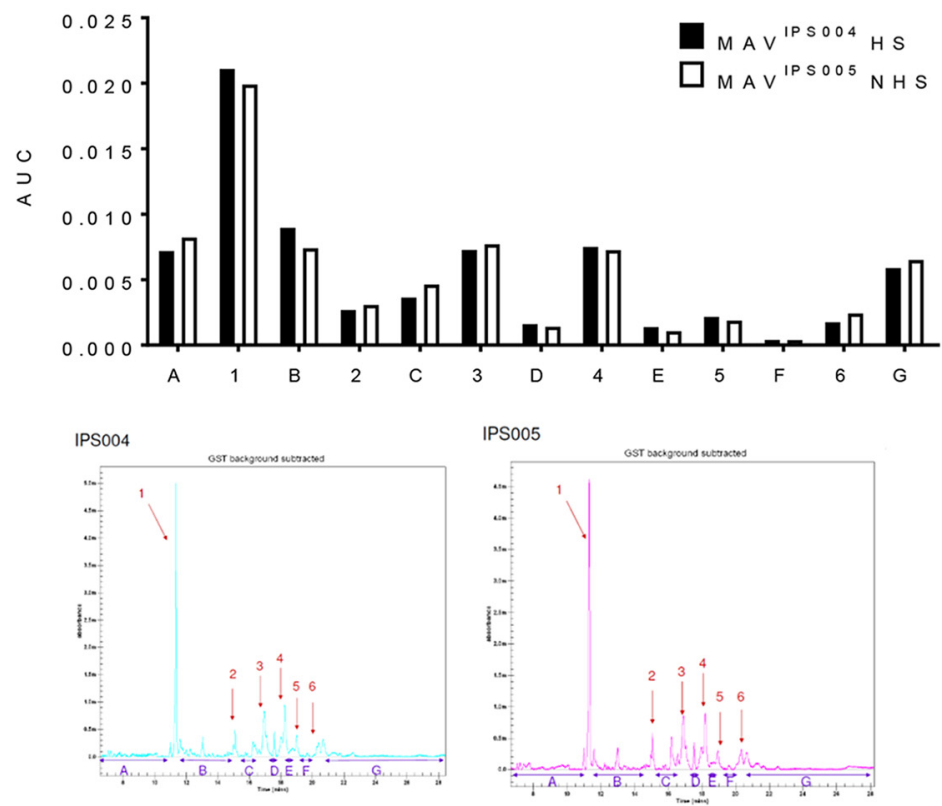

D

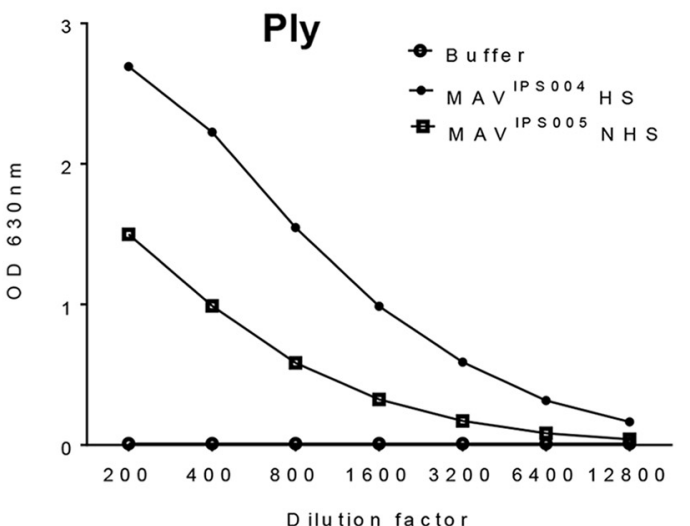

E

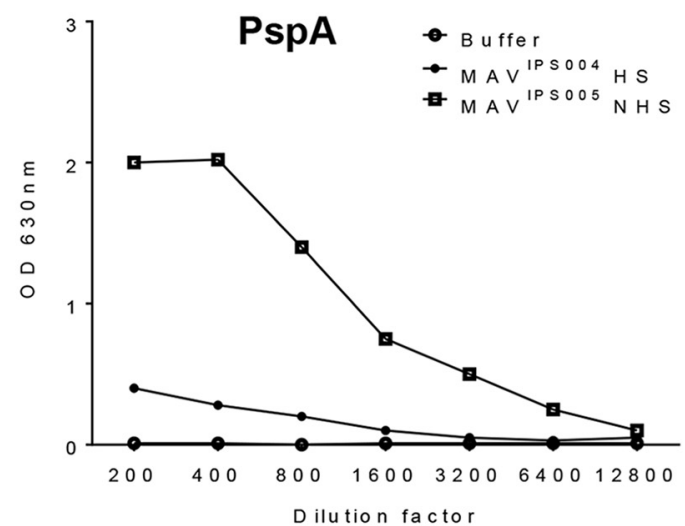

FIG 5 Comparison of MAV preparations cultured at $30^{\circ} \mathrm{C}$ or $37^{\circ} \mathrm{C}$. (A) MAV preparations were made by culture at $30^{\circ} \mathrm{C}$ before transfer to $37^{\circ} \mathrm{C}$ for $30 \mathrm{~min}\left(\mathrm{MAV}^{\mathrm{IPS} 004}\right)$ or culture at $37^{\circ} \mathrm{C}\left(\mathrm{MAV}^{\mathrm{IPS} 005}\right)$. Protein bands were compared using a Coomassie gel (top). Three micrograms (lanes 7 
$1 \times 10^{4}$ CFU of TIGR4 S. pneumoniae after $6 \mathrm{~h}$. When culled at $24 \mathrm{~h}$ postchallenge, colonies were recovered from the blood of over $65 \%$ of the mice given sera from buffervaccinated rabbits, while there no colonies were detected in mice given sera from MAVIPS004-vaccinated rabbits (Fig. 6D). Two mice (16\%) developed septicemia after passive administration of sera from rabbits given the Prevenar vaccine. In an alternative sepsis model, mice were challenged by intravenous inoculation with $5 \times 10^{5} \mathrm{CFU}$ of $S$. pneumoniae TIGR4 or ATCC BAA-1662 (serotype 18C S. pneumoniae) strains after preincubation of the bacteria for $1 \mathrm{~h}$ in 100\% serum obtained from rabbit immunized with MAVIPS014, the Prevenar vaccine, or buffer controls. Mice were culled at $4 \mathrm{~h}$ to assess the rate of bacterial clearance from the blood by quantifying the number of CFU. Those challenged with the TIGR4 strain were almost completely protected against infection if the bacteria were incubated in sera from either MAVIPS014- or Prevenar-vaccinated rabbits prechallenge (Fig. 6E). Preincubation of the $18 \mathrm{C}$ strain prior to intravenous challenge in sera from either MAVIPS014_ or Prevenar-vaccinated rabbits prechallenge reduced the number of bacterial CFU recovered from the blood by over $1 \log _{10}$ compared to the number obtained with preincubation in sera from buffer-vaccinated rabbits (Fig. 6F). To support these data, vaccination with MAVIPS014 was compared to that with a buffer control in a protection study, which demonstrated that mice given a three-dose vaccination schedule with MAVIPS014 were protected against the development of fatal infection after pneumonia challenge with TIGR4 (Fig. 7A). The effects of vaccination on the inflammatory response to pneumonia challenge was assessed using flow cytometry of lung and BALF cell populations $24 \mathrm{~h}$ after intranasal infection with TIGR4. Despite clear reductions in the numbers of CFU in the lungs and blood of vaccinated mice, there were no differences in the proportions of neutrophils in BALF between MAVIPS014- and buffer-vaccinated mice, indicating that MAVIPS014 vaccination resulted in an increased $B A L F$ neutrophil response for the level of bacterial infection (Fig. 7B and C). In addition, in lung homogenates, MAVIPS014-vaccinated mice had reduced proportions of neutrophils and macrophage lineage cells and a corresponding increase in T cells (Fig. 7D). The increase in the T cell proportion within lung homogenates in vaccinated mice did not alter the CD4/CD8 proportions compared to the data for control mice (data not shown). Lung homogenate cytokine levels were variable between mice but showed increased interleukin-1 (IL-1), IL-6, tumor necrosis factor alpha (TNF- $\alpha$ ), and IL-10 responses in vaccinated mice compared to the controls, again suggesting that vaccinated mice were able to mount a more sustained inflammatory response than the controls (Fig. 7E to $\mathrm{H}$ ). BALF and blood cytokine levels were, in general, too low and variable for consistent patterns to be identified.

Overall, these results indicate that the MAV is able to protect against S. pneumoniae infection with the homologous strain or a heterologous strain at a level of protection similar to that provided by the Prevenar vaccine and is associated with significant changes in the inflammatory response to pneumonic infection.

\section{DISCUSSION}

Although the existing childhood conjugated capsular polysaccharide S. pneumoniae vaccines are highly effective, both the lack of protection against nonvaccine serotypes and convincing evidence of serotype replacement in vaccinated populations, as well as

FIG 5 Legend (Continued)

and 9) and $5 \mu \mathrm{g}$ (lanes 8 and 10) of each MAV was loaded; immunoblots of the MAV preparations were also probed for the presence of the key S. pneumoniae protein antigens (PlyD6, PspA) and Hsps (Hsp70, Hsp60). (B) Capillary gel electrophoresis (CGE) analysis was conducted to determine the protein constituents of each preparation. Each peak is denoted by a number, and interpeak regions are marked by a letter. Quantification of peaks is shown in the bar chart on top. CGE traces are shown below. (C) Both MAVIPS004 and MAVIPS005 were used to generate antisera using vaccination experiments in mice. Sera recovered from mice vaccinated with either preparation were analyzed using flow cytometry assays of IgG binding to live S. pneumoniae bacteria (serotypes 1, 2 [D39], 4 [TIGR4], 6B, 8, 19A, 22F, and 23F), and results are represented as the mean fluorescence intensity (MFI) in the appropriate gate. Q1, quadrant 1. (D and E) ELISAs detecting anti-Ply (D) and anti-PspA (E) responses were conducted in duplicate. Sera from the experiments described above were diluted, as shown on the $x$ axis, and the $\mathrm{OD}_{450}$ was measured for each MAV and a buffer control. Abbreviations: MAV, multiantigen vaccine; HS, heat shocked; NHS, non-heat shocked; MK, molecular weight marker; AUC, area under the curve. 
A

0
0
5
0
0
$=$
-
$\varepsilon$
0
1
0
0
0
0
$\infty$
TIGR4 (IN)

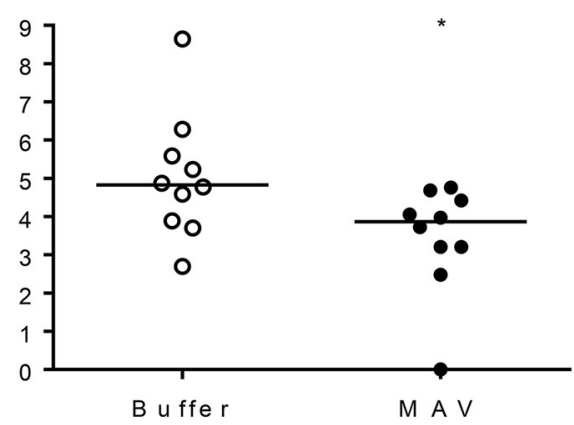

C

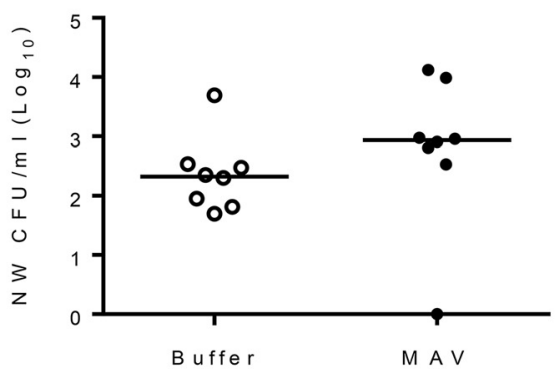

E

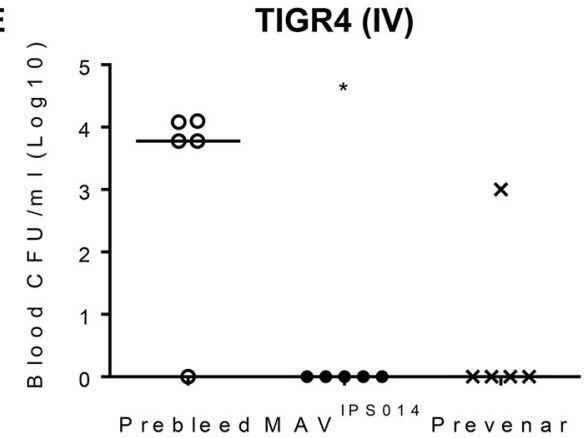

B

TIGR4 (IN)

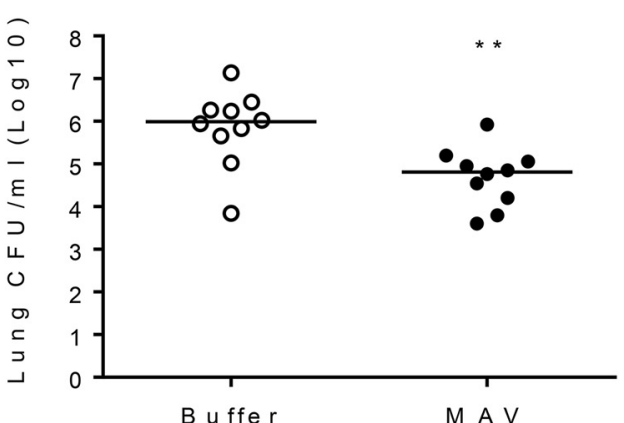

D

TIGR4 (IP)

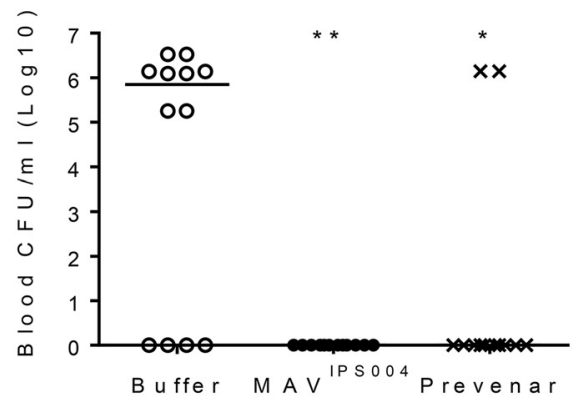

F

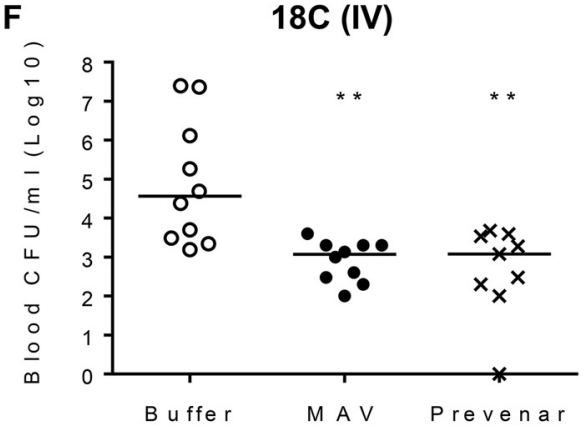

FIG 6 Vaccination with MAV preparations protects mice against S. pneumoniae challenge. (A and B) Number of CFU in the lung (A) and blood (B) $24 \mathrm{~h}$ after challenge by intranasal (IN) inoculation with $1 \times 10^{7}$ CFU of the S. pneumoniae TIGR4 strain in mice vaccinated twice subcutaneously with $75 \mu \mathrm{g}$ of MAV or a negative-control buffer ( $n=10$ per group). (C) Number of CFU in nasal wash (NW) specimens 2 weeks after nasopharyngeal colonization with $5 \times 10^{6}$ CFU of S. pneumoniae TIGR4 of mice vaccinated twice subcutaneously with $75 \mu \mathrm{g}$ of MAV or a negative control buffer ( $n=$ 8 per group). (D) Number of CFU in blood $6 \mathrm{~h}$ after challenge by intraperitoneal (IP) inoculation of $1 \times 10^{4}$ CFU of the S. pneumoniae TIGR4 strain into mice passively vaccinated with $200 \mu$ l of sera from rabbits vaccinated three times with $375 \mu \mathrm{g}$ of MAVIPS004 or twice with $0.2 \mathrm{ml}$ of the Prevenar vaccine or a negative-control buffer ( $n=12$ per group). (E and F) Number of CFU in the blood of mice $4 \mathrm{~h}$ after challenge by intravenous (IV) inoculation with $5 \times 10^{5}$ CFU of the S. pneumoniae TIGR4 (E) or ATCC BAA-1662 (18C) (F) strain that was incubated preinoculation in sera obtained from rabbits vaccinated with MAVIPS014, the Prevenar vaccine, or a negative-control buffer $(n=5$ to 10$)$. For all panels, each symbol represents data from a single mouse, and horizontal bars represent median values. Statistical significances were calculated using a Mann-Whitney $t$ test (A to $D)$ or Dunnett's multiple-comparison test (E and F). Significance abbreviations: *, $P<0.05 ;{ }^{* *}, P<0.01$.

the high cost of these vaccines, have stimulated continued interest in alternative vaccine approaches $(38,39)$. Vaccines based on protein antigens could overcome these disadvantages, allowing production of relatively inexpensive vaccines that target cross-protective antigens (40-43). Presentation of a large number of protein antigens derived from a whole-cell approach has the additional potential advantages of inducing immune responses to multiple antigens, thereby potentially avoiding the development of vaccine escape mutants and inducing stronger cross-protective responses $(44,45)$. 

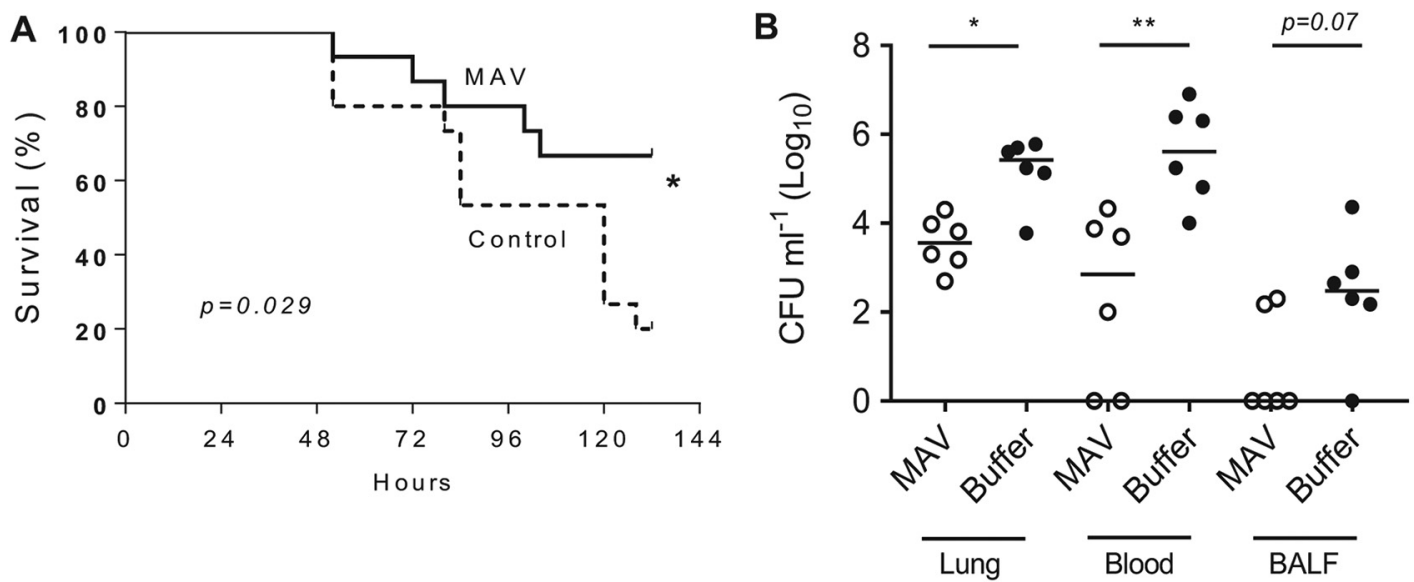

C

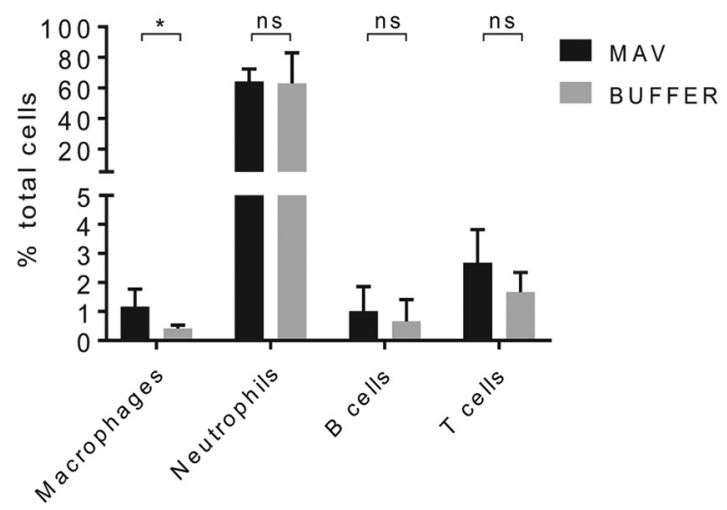

D

\section{LUNGS}

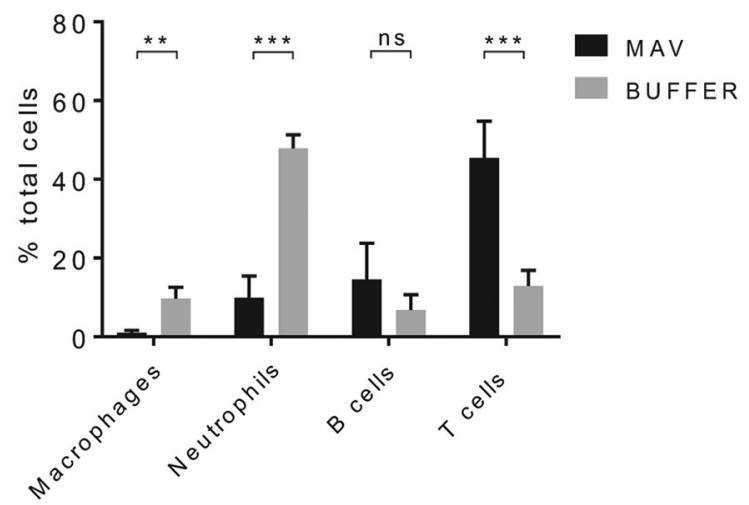

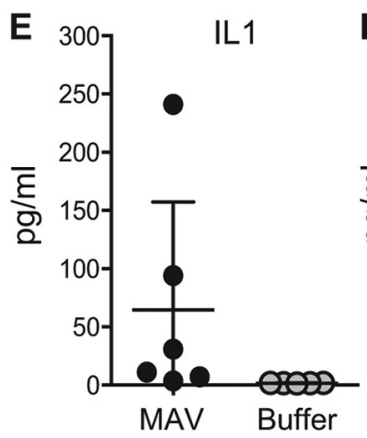
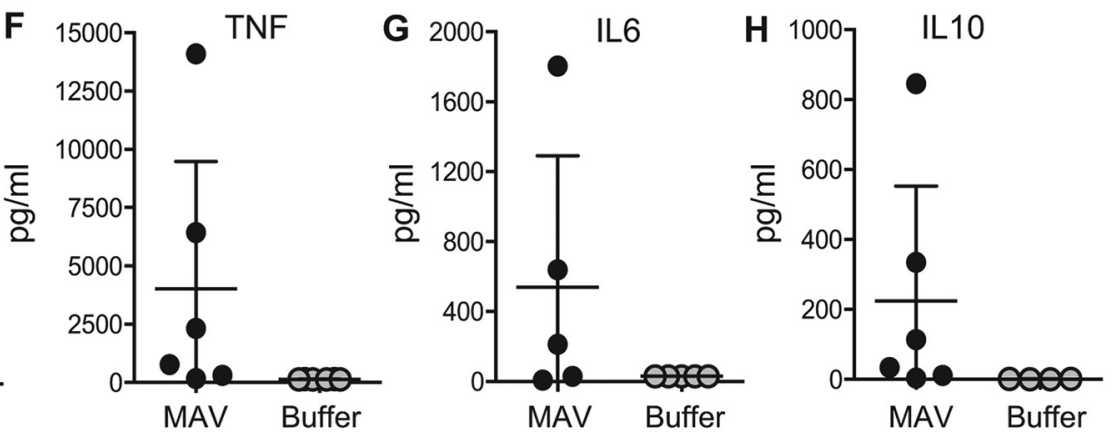

FIG 7 Vaccination with MAV preparations increases the survival of mice and alters the inflammatory response after S. pneumoniae TIGR4 pneumonia challenge. (A) Percent survival of mice over 6 days after challenge by intranasal inoculation with $1 \times 10^{7}$ CFU of the S. pneumoniae TIGR4 strain of mice that had been vaccinated three times (days 1,10 , and 22) intraperitoneally with $75 \mu \mathrm{g}$ of

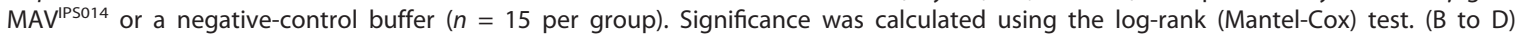
Numbers of CFU in target organs (B) and inflammatory cell populations in BALF (C) and lung (D) $24 \mathrm{~h}$ after challenge with $1 \times 10^{7}$ CFU of the S. pneumoniae TIGR4 strain in MAVIPS014-vaccinated and control mice. Inflammatory cell data are shown as a percentage of the total cells recovered from the lungs of MAV- and buffer-vaccinated mice; CFU data show the number of CFU in lung, blood, or BALF recovered $24 \mathrm{~h}$ after challenge, with each symbol representing data from a single mouse and horizontal bars representing median values. ( $\mathrm{E}$ to $\mathrm{H}$ ) Lung homogenate cytokine levels $24 \mathrm{~h}$ after challenge with $1 \times 10^{7} \mathrm{CFU}$ of the S. pneumoniae TIGR4 strain in MAVIPS014-vaccinated and control mice. For panels $B$ to $\mathrm{H}$, statistical significances were calculated using a Mann-Whitney $t$ test. Significance abbreviations: ${ }^{*}, P<0.05$; ${ }^{* *}, P<0.01$; ${ }^{* * *}, P<0.001$; ns, not significant.

The data presented here show that a novel S. pneumoniae multiple-protein-antigen vaccine approach induces antibody that recognizes homologous and heterologous strains and protects against invasive pneumonia and sepsis. The MAV approach uses a whole-cell lysate that has been manipulated to increase the expression of Hsps, and the anion-exchange column and running buffer are optimized for the capture of 
known S. pneumoniae antigens as well as Hsps. Proteomic analysis confirmed that the MAV approach alters the relative levels of S. pneumoniae proteins within the preparation compared to those in a simple bacterial lysate, with altered expression of a total of 209 proteins of the 627 proteins analyzed. The S. pneumoniae TIGR4 strain actually contains approximately 2,000 genes (46), so the number of proteins with altered content in the MAV may, in fact, be substantially larger. Both immunoblotting and TMT-MS confirmed that the MAV had an increased Hsp content compared to that of a simple lysate. In addition, there was increased expression of multiple surface proteins, including known protective antigens (mainly lipoproteins), although there were also reduced amounts of other protein antigens that are known to induce protective immunity in mice.

Importantly, whole-cell ELISAs, the MSD assay for IgG responses to individual antigens, and a flow cytometry assay of IgG binding to S. pneumoniae all demonstrated enhanced antibody responses in mice vaccinated with the MAV compared to the HKL, demonstrating the benefit of the MAV approach in making a potentially more effective vaccine. Unlike HKL, MAV induced antibody responses to all the protein antigens tested using the MSD system, suggesting that the MAV approach may induce antibody responses to a very high proportion of the proteins in the preparation. Furthermore, although iTRAQ demonstrated a reduced content in the MAV preparation compared to that in HKL for the important antigens PspC and Ply, vaccination with MAV still induced stronger lgG responses to these antigens, when tested using the MSD assay, than vaccination with HKL. These data again suggest that the MAV approach enhances immunogenicity. The improved serological responses to MAV compared to HKL might be predicted to be due to the increased Hsp content leading to the formation of Hsp-peptide complexes and thereby increasing the antigen-presenting ability $(27,29)$. A consistent shift of culture temperature to $42^{\circ} \mathrm{C}$ was difficult when MAV production was scaled up using bioreactors. This required a change in culture conditions to $30^{\circ} \mathrm{C}$ with a switch to $37^{\circ} \mathrm{C}$ for the final 30 min before harvest, conditions which also mimic the transfer of pneumococci from the nasopharynx to the bloodstream during invasive disease. In the studies reported here, MAV prepared under these conditions demonstrated similar antigenicity in comparison to a MAV preparation cultured at $37^{\circ} \mathrm{C}$ throughout.

Data from a pneumonia model and two separate mouse models of sepsis demonstrated that active or passive vaccination with MAV improved protection against $S$. pneumoniae. Time course experiments demonstrated that vaccination with the MAV preparation delayed and protected against lethal infection. The total $T$ cell populations in the lung were also increased in MAV-vaccinated mice. This effect in T cell proportions probably reflects the accumulation of antigen-specific cells during pneumonia in infected tissue, but further experiments would be needed to confirm this. Overall, the data demonstrate that vaccination with MAV had significant effects on the inflammatory response during $S$. pneumoniae pneumonia that are likely to contribute to protective efficacy, with improved neutrophil recruitment into the alveolar space and increased numbers of $T$ cells within the lung parenchyma.

MAV also induced lgG that bound to heterologous strains in the flow cytometry assay, an assay which correlates with improved phagocytosis in vitro and protection in mouse models $(31,47,48)$. Indeed, in a mouse model of sepsis, passive vaccination with sera from MAV-vaccinated rabbits gave a level of protection against both the homologous TIGR4 and heterologous 19C strains similar to that achieved with passive vaccination with sera from Prevenar-vaccinated rabbits. Whether vaccination with MAV can induce stronger protection than vaccination with HKL or HKWC in the mouse models was not tested; due to the relatively low sensitivity of the mouse models, this is likely to require inappropriately large numbers of mice per test group. A lack of sensitivity is also why vaccination followed by disease challenge experiments would be unlikely to show any significant differences between MAV preparations with and without heat shock steps and why these experiments were not performed. The level of protection varied between models, with complete prevention of septicemia being seen in 
some models, e.g., intravenous TIGR4 infection, but reductions in the number of bacterial CFU only in the blood being seen in others (e.g., the serotype $18 \mathrm{C}$ sepsis model). The latter is likely to slow the progression of disease but not prevent fatal infection. Vaccination with MAV failed to protect against colonization, but this is not that surprising, given the lack of detectable antibody in nasal washes and previous data showing that antiprotein antibody is often ineffective at reducing the number of nasopharyngeal S. pneumoniae CFU (in some cases, even when Th17-mediated immunity has also been induced) $(9,10,49)$. Prevention of nasopharyngeal colonization will probably require vaccines that induce strong cell-mediated immune mechanisms, which may require vaccination in combination with specific adjuvants $(24,46,50)$. This would be an important area for further investigation. Future experiments should also assess whether MAV vaccination modulates pulmonary inflammatory responses to S. pneumoniae pneumonia challenge.

The MAV approach described here can induce the cross-protective immunogenicity of protein antigens which stimulate antibody and perhaps Th17 cell responses $(30,51)$ without requiring the identification of specific protective antigens or the production of recombinant proteins for inclusion in subunit vaccines. MAV requires limited downstream processing and rapidly produces a high yield of vaccine product, considerably reducing vaccine costs and making the vaccine more likely to be affordable in lowand middle-income countries. The MAV approach therefore offers a promising opportunity for a novel next-generation S. pneumoniae vaccine and has recently completed a phase I trial in 36 subjects (ClinicalTrials.gov registry number NCT0257635 [52]).

\section{MATERIALS AND METHODS}

Bacterial strains and growth conditions. S. pneumoniae was grown in either Todd-Hewitt medium containing 5\% yeast extract (THY; Oxoid, UK) or defined Hoeprichs' medium and on 5\% blood Columbia agar (Oxoid) plates containing $5 \%$ defibrinated horse blood (TCS Biosciences, UK) at $37^{\circ} \mathrm{C}$ in $5 \% \mathrm{CO}_{2}$. Growth in medium was assessed using the optical density at $580 \mathrm{~nm}\left(\mathrm{OD}_{580}\right)-\mathrm{OD}_{600}$, with bacterial stocks grown to mid-log phase $\left(\mathrm{OD}_{580}, 0.4\right.$ to 0.5$)$ before storage in $10 \%$ glycerol at $-80^{\circ} \mathrm{C}$. Bacterial counts were determined as previously described (53-55) by plating 10-fold serial dilutions of aliquots on $5 \%$ blood Columbia agar plates after overnight incubation at $37^{\circ} \mathrm{C}$ in $5 \% \mathrm{CO}_{2}$. The TIGR4 strain-derived MAV hs was made from S. pneumoniae TIGR4 (American Type Culture Collection [ATCC] strain ATCC BA334), and MAV batches IPS004, IPS005, and IPS014 were made from strain TIGR4 B7.1 (PlyD6), which expresses an inactivated pneumolysin toxin, made as previously described (29). Additional S. pneumoniae strains used in this study were D39 (serotype 2); 0100093 (serotype 3); 23F, a gift from B. Spratt (Imperial College London); 18C, from ATCC (ATCC BAA-1662); EF3030 (serotype 19F), a gift from D. Briles (University of Alabama); and strain 1777/39 (19A), a gift from J. Paton (University of Adelaide).

MAV, heat-killed lysate, and heat-killed whole-cell preparation. MAV preparations were cultured in Hoeprichs' media (made in-house) in 1-liter shake flasks to an $\mathrm{OD}_{600}$ of 1.2. The MAVhs preparation was made from TIGR4 cultured at $37^{\circ} \mathrm{C}$ before switching to $42^{\circ} \mathrm{C}$ for 30 min. MAVIPS004 and MAVIPS005 were made from S. pneumoniae TIGR4 B7.1 (PlyD6) in 1-liter bioreactors, with MAV ${ }^{\mathrm{IPS} 004}$ cultured at $30^{\circ} \mathrm{C}$ and then switching to $37^{\circ} \mathrm{C}$ for $30 \mathrm{~min}$ before harvest and MAVIPS005 cultured at $37^{\circ} \mathrm{C}$ throughout. The bacteria were then centrifuged twice with wash buffer ( $40 \mathrm{mM}$ Tris, $150 \mathrm{mM} \mathrm{NaCl}, 1 \mathrm{mM} \mathrm{MgCl}$, $\mathrm{pH}$ 8.0) and incubated with lysis buffer ( $40 \mathrm{mM}$ Tris, $20 \mathrm{mM} \mathrm{NaCl}, 1 \mathrm{mM} \mathrm{MgCl}{ }_{2}, 0.5 \%$ [wt/vol] sodium deoxycholate $[\mathrm{NaDOC}], \mathrm{pH} 8.0$ ) for $1 \mathrm{~h}$ at $4^{\circ} \mathrm{C}$, before homogenization (EmulsiFlex $\mathrm{C} 5$ high-pressure homogenizer; Avestin, Germany) and incubation with $0.1 \%$ (wt/vol) octaethylene glycol monododecyl ether $\left(\mathrm{C}_{12} \mathrm{E}_{8}\right)$ for $4 \mathrm{~h}$ at $4^{\circ} \mathrm{C}$. Sample supernatants were harvested using a 5-ml Capto Q column (GE Healthcare, UK). Protein was eluted and collected as $5-\mathrm{ml}$ fractions at $400 \mathrm{mM}$ and $500 \mathrm{mM}$ concentrations of $\mathrm{NaCl}$. $\mathrm{MAV}^{\mathrm{IPS} 014}$ was made as described above using TIGR4 B7.1 (PlyD6) culturing at $30^{\circ} \mathrm{C}$ and then switching to $37^{\circ} \mathrm{C}$ for $30 \mathrm{~min}$. MAVIPS014 was then lysed in NaDOC (0.5\%) and Triton X-100 (1\%). MAVIPS004 and MAVIPS014 contained similar levels of detoxified Ply when measured by ELISA (32) and the absence of hemolysis in the red blood cell lysis assay. For heat-killed lysates (HKL) of TIGR4 and heat-killed whole-cell (HKWC) preparations, TIGR4 was also cultured in Hoeprichs' medium in 1-liter shake flasks at $37^{\circ} \mathrm{C}$ to an $\mathrm{OD}_{600}$ of 1.2 , followed by killing by incubation at $65^{\circ} \mathrm{C}$ for $45 \mathrm{~min}$, which was confirmed by culture on Columbia agar plates. For the HKL, lysis was performed using $\mathrm{NaDOC}$ and high-pressure homogenization as described above. $\mathrm{C}_{12} \mathrm{E}_{8}$ was added to both the HKL and HKWC before filtration.

Vaccine characterization. Vaccine samples were analyzed with SDS-PAGE using a 4 to $12 \%$ NuPAGE gel (Invitrogen, USA), MES (morpholineethanesulfonic acid; Invitrogen) running buffer, and staining for protein with InstantBlue (Expedeon, UK). For Western blot analysis, gels were subsequently blotted onto polyvinylidene difluoride (PVDF) membranes and probed with the appropriate antibodies diluted in 5\% milk-phosphate-buffered saline (PBS): anti-Hsp60 (GroEL; catalog number SPS-875; StressGen, USA) at 1:2,000, antipneumolysin (catalog number ab49568; Abcam, UK) at 1:2,000, anti-Hsp70 (made in-house) at 1:500, and anti-PspA (catalog number sc17483; Santa Cruz, USA) at 1:1,000. Protein concentrations were determined using bicinchoninic acid (BCA) protein assays (Pierce, USA). For hemolysis assays, the 
vaccine preparations were serially diluted in PBS, an equal volume of $2 \%$ defibrinated horse blood was added, and the mixture was incubated at $37^{\circ} \mathrm{C}$ for $30 \mathrm{~min}$, followed by centrifugation at $1,000 \times g$ for 1 min and measurement of the absorbance of the supernatants at $490 \mathrm{~nm}$.

Capillary gel electrophoresis. Analysis of the samples by capillary gel electrophoresis (CGE) was conducted by deltaDOT, London BioScience Innovation Centre, using the high-performance capillary electrophoresis (HPCE) platform Peregrine. Peaks were manually selected, and raw data are expressed as the peak area corrected for migration time and then expressed as a percentage of the total corrected peak area or the area under the curve (inclusive of the Triton X-100 peak [peak 1] and interpeak regions [regions A to G]) normalized to an external protein standard. This compensates for day-to-day variation and allows comparison between runs on different sections of the capillary. Peak 1 is the detergent Triton X-100 peak.

In vitro assays. S. pneumoniae whole-cell ELISAs were performed using bacterial cultures at an $\mathrm{OD}_{580}$ of 0.4 to 5 , alkaline phosphatase (AP)-conjugated secondary antibodies, and the substrate para-nitrophenylphosphate (pNPP; Sigma) as previously described $(56,57)$. The absorbance was read at $450 \mathrm{~nm}$, and the readings obtained at $630 \mathrm{~nm}$ were subtracted (VersaMax). The ELISA titer represents the theoretical sample dilution that would result in an $\mathrm{OD}_{450}$ reading minus $\mathrm{OD}_{630}$ reading of 0.1 . For detection of antiPly and anti-PspA antibodies, the appropriate antigen was diluted in carbonate buffer to a final concentration of $1 \mu \mathrm{g} / \mathrm{ml}, 100 \mu \mathrm{l}$ was transferred to each well of a 96-well MaxiSorp ELISA plate, and the plate was incubated overnight at $4^{\circ} \mathrm{C}$. The plates were then washed 3 times with ELISA wash buffer (1\% [vol/ vol] Tween 20-PBS), blocked for $1 \mathrm{~h}$ with block buffer (1\% [wt/vol] bovine serum albumin [BSA]-PBS) at $37^{\circ} \mathrm{C}$, and then washed as described above. Serum samples were diluted to a starting dilution of $1 / 100$ to $1 / 300$. Doubling dilutions of the pooled serum samples were assayed in duplicate. The plates were incubated at $37^{\circ} \mathrm{C}$ for $1 \mathrm{~h}$ and washed, and goat anti-mouse lgG-horseradish peroxidase diluted to 1/ 20,000 was added before incubation at $37^{\circ} \mathrm{C}$ for $1 \mathrm{~h}$ before washing. Tetramethylbenzidine substrate was added before incubation at room temperature in the dark. The plates were read at $\mathrm{OD}_{450}$, and endpoint titers were calculated using the linear part of each titration curve. IgG surface binding was assessed using previously described flow cytometry assays $(31,47,48)$ and species-appropriate secondary antibodies: anti-human IgG secondary antibody (1:200) conjugated to phycoerythrin (PE; SigmaAldrich) and goat anti-mouse IgG conjugated to fluorescein isothiocyanate (Bio-Rad, USA). Fluorescenceactivated cell sorting (FACS) analysis of bacterial cells was performed on a FACSVerse flow cytometer (Becton, Dickinson, USA) and with FACSuite (Becton, Dickinson) and FlowJo (Becton, Dickinson) software. FACS surface binding comparisons of $\mathrm{MAV}^{\mathrm{IPS} 004}$ and $\mathrm{MAV}^{\mathrm{IPS} 005}$ were conducted by ImmBio, as follows: $100 \mu \mathrm{l}$ of bacterial suspension was placed in each 5-ml FACS tube, and the tubes were incubated overnight at $4^{\circ} \mathrm{C}$. Cells were washed with PBS-0.1\% Tween 20 (PBS-T). Preadsorbed serum samples were serially diluted (2-fold), starting from 1 in 25, to 1 in 800 in PBS-1\% BSA. Cells and sera were incubated together for $2 \mathrm{~h}$ at room temperature and then washed with PBS-T. Goat anti-mouse IgG detection antibody in PBS-1\% BSA was added, and the mixture was incubated for $2 \mathrm{~h}$. Cells were then fixed with formalin for $30 \mathrm{~min}$ at room temperature. Following washing in PBS-T, samples were resuspended in PBS-1\% fetal calf serum. The mean fluorescence intensity (MFI) was read by flow cytometry, with 100,000 events being required for each sample. The MFI multiplied by the number of cells in quadrant 1 is shown for each serotype. This represents the degree of antibody binding to each serotype. Multiplexed electroluminescence assays were conducted as previously described $(32,58,59)$ using a Meso Scale Discovery (MSD; MD, USA) platform assay (60) with $5 \mu \mathrm{g} / \mathrm{ml}$ of S. pneumoniae proteins and $10 \mu \mathrm{g} / \mathrm{ml}$ of capsular polysaccharide. After incubation of each antigen-coated plate with blocking agent, washing, and incubation with diluted test serum for $45 \mathrm{~min}$ at room temperature, the plates were washed and MSD assay sulfo tag-labeled goat anti-mouse IgG secondary antibody was added for reading using an MSD Sector Imager 2400 or 6000 apparatus.

Quantitative comparison of protein content using TMT and MS. The tandem mass tags (TMT) labeling procedure followed the manufacturer's recommendation (Thermo Fisher). In brief, protein lysates from two replicates of HKL and MAV were reduced with tris(2-carboxyethyl) phosphine and alkylated with iodoacetic acid before an overnight acetone precipitation. Protein pellets were digested overnight at $37^{\circ} \mathrm{C}$ in $200 \mathrm{mM}$ TEAB solution containing $2.5 \mu \mathrm{g}$ trypsin (Promega), with the resulting peptides being labeled with different isobaric tags (TMTs 126 to 128). Labeled peptides were mixed and injected onto an XBridge $\mathrm{C}_{18}$ column (particle size, $5 \mu \mathrm{m} ; 4.6 \mathrm{~mm}$ [inside diameter] by $25 \mathrm{~cm}$ long; Waters) for first-dimension high-pH reversed-phase high-performance liquid chromatography (HPLC) separation under a linear gradient consisting of mobile phase $\mathrm{A}(10 \mathrm{mM}$ ammonium formate, $\mathrm{pH} 10.0)$ and up to $70 \%$ mobile phase $B(90 \%$ acetonitrile in mobile phase $A)$ for $2 \mathrm{~h}$ at flow rate of $0.5 \mathrm{ml} / \mathrm{min}$, using a Jasco system consisting of an autosampler, semimicro-HPLC pumps, and a UV detector. The eluted fractions were collected, concatenated into 18 tubes, and vacuum dried.

Nano-liquid chromatography and tandem mass spectrometry (MS/MS) were performed using a U3000 direct nano system coupled with a nano electrospray and LTQ-Orbitrap Discovery mass spectrometer (Thermo). The $12 \mathrm{HPLC}$ fractions containing the mixture of fourplex-labeled peptides were resuspended in $0.1 \%$ formic acid, and each was separated on a PepMap $C_{18}$ reversed-phase nano column (particle size, $3 \mu \mathrm{m} ; 100 \AA \AA ; 50-\mathrm{cm}$ length; Thermo) under a column flow rate of $0.3 \mu \mathrm{l} / \mathrm{min}$ using a linear gradient of $95 \%$ acetonitrile and $0.1 \%$ formic acid at 5 to $25 \%$ for $180 \mathrm{~min}, 25$ to $32 \%$ for $20 \mathrm{~min}$, and 32 to $90 \%$ for $10 \mathrm{~min}$. MS scan and MS/MS fragmentation were carried out in the LTQ-Orbitrap Discovery mass spectrometer, using 2 cycles of top 3 data-dependent acquisition with the dynamic exclusion mode enabled and a total cycle time of approximately 30 ms. The first cycle used collision-induced dissociation (CID) fragmentation-generating spectra for peptide sequencing, and the second used high-energy-CID (HCD)-generating spectra both for peptide sequencing and for relative quantitation via report ions. 
Mass spectrum processing, database searching, and quantitation against the UniProt S. pneumoniae FASTA database (release 2014.04.03) were performed using Thermo Proteome Discoverer (version 1.4) software with a built-in Sequest program. Spectra from the 12 fractions were added together as one sample during the search. Initial mass tolerances by MS were set to 10 ppm. Up to two missed tryptic cleavages were considered. Methionine oxidation was set as a dynamic modification, whereas carboxymethylation on cysteine and TMT 6-plex labels on the N-terminal amino acid and the lysine side chain were set as static modifications. Peptides at rank 1 with a high confidence were considered to be unambiguously sequenced. Quantification was based on the relative abundances of the TMT tag as the reporter ions for each peptide in the HCD spectra with all TMT channels present. Ratios were calculated from the relative abundances of each labeled peptide in the sample based on reporter ion intensities, and for every protein identified, each was assigned a series of quantification ratios relative to each group.

In vivo methods. All in vivo experiments using mice were performed according to United Kingdom national guidelines for animal use and care. Experiments performed at UCL were approved by the UCL Biological Services Ethical Committee and the UK Home Office (project license PPL70/6510). Experiments used 6-week-old outbred female CD1 mice obtained from Charles River Laboratories. Mice were vaccinated with $75 \mu \mathrm{g}$ of protein in $100 \mu \mathrm{l}$ PBS using either intraperitoneal injection at days 0,14 , and 28 or subcutaneous vaccination on days 0 and 21 . Tail bleeds ( $5 \mu$ l per mouse) were collected on day 42 , and mice were challenged with $S$. pneumoniae on day 49. For the pneumonia model, mice under isoflurane (4\%; MiniRad) anesthesia were inoculated with $5 \times 10^{6}$ CFU of S. pneumoniae in PBS intranasally. After either 24 or $48 \mathrm{~h}$, the mice were euthanized with pentobarbitone, and blood, serum, bronchoalveolar lavage fluid (BALF), the lungs, and the spleen were collected as previously described $(9,31,50,61)$. Lungs and spleens were macerated through a $0.2-\mu \mathrm{m}$-pore-size filter. For the colonization model, mice were anesthetized with aerosolized isoflurane (4\%) and inoculated with $5 \times 10^{6} \mathrm{CFU}$ of S. pneumoniae suspended in $10 \mu \mathrm{l}$ of PBS. At designated time points postinfection, the mice were culled and nasal washes were obtained by retrograde washing of the nares with $500 \mu \mathrm{l}$ PBS via the trachea. To assess survival, mice were vaccinated by intraperitoneal inoculation with $75 \mu \mathrm{g}$ of the MAV ${ }^{\mathrm{IPS} 014}$ vaccine together with the adjuvant system (catalog number S6322; Sigma) on days 1, 10, and 22 before intranasal challenge with $1 \times 10^{7}$ CFU of S. pneumoniae TIGR4 on day 50. Disease development was monitored over 6 days, and mice were culled when they exhibited signs of severe disease (61). For the passive transfer model, mice were injected intraperitoneally with $200 \mu \mathrm{l}$ of serum harvested from rabbits vaccinated by subcutaneous injection of $375 \mu \mathrm{g}$ MAV on days 0,21 , and 35 or two 200- $\mu$ l Prevenar 13 doses on days 0 and 21 at Envigo, UK. Mice were challenged $6 \mathrm{~h}$ later by intraperitoneal inoculation of $1 \times 10^{4} \mathrm{CFU}$ of S. pneumoniae and culled at $24 \mathrm{~h}$ to obtain blood samples for plating. For the sepsis model, sera from vaccinated mice or rabbits were transferred to mice via intravenous injections into the lateral tail vein. After $4 \mathrm{~h}$, the mice were inoculated intravenously with $5 \times 10^{5} \mathrm{CFU}$ of $\mathrm{S}$. pneumoniae and culled $4 \mathrm{~h}$ later to collect blood. For the preopsonization clearance model, S. pneumoniae bacteria were opsonized by incubation in $100 \%$ rabbit immune serum for $1 \mathrm{~h}$ at $37^{\circ} \mathrm{C}$, and then $5 \times 10^{5} \mathrm{CFU}$ of $\mathrm{S}$. pneumoniae was inoculated intravenously into the mice, which were then culled $4 \mathrm{~h}$ later to obtain blood for CFU quantification by plating. To calculate the numbers of target organ CFU, aliquots of blood and lung and spleen tissues were plated at appropriate dilutions on $5 \%$ blood Columbia agar plates containing $5 \mathrm{mg} / \mathrm{ml}$ gentamicin (Sigma). Additional experiments to raise antisera with different vaccine preparations were performed at a commercial organization, Churchill Applied Biotechnology Ltd., according to institutional guidelines under its UK Home Office project license. For these experiments, six groups of female CD-1 mice $(n=10)$ were immunized subcutaneously with $0.75 \mu \mathrm{g}$ of MAV on day 0 and day 21. Mice were culled on day 35 and terminally bled, and serum was prepared for the investigation of antibody responses.

Flow cytometry phenotypic screening of inflammatory cell populations. The lungs of vaccinated mice were harvested $24 \mathrm{~h}$ after infection, and single-cell suspensions were prepared by homogenizing the tissues and filtering them with 100- $\mu \mathrm{m}$-mesh-size cell strainers. Red blood cells were lysed with red blood cell lysis buffer (catalog number 420301; BioLegend), and washed cells were resuspended at a concentration of $10^{6}$ cells $/ \mathrm{ml}$ in blocking buffer (PBS-1\% BSA containing anti-Fc receptor antibodies [TruStain FCX; BioLegend]). The cells were seeded in round-bottom 96-well plates (100 $\mu \mathrm{l} /$ well) and incubated for $30 \mathrm{~min}$ on ice. Cells were washed and stained with a mixture of antibodies diluted 1:100 for 30 min in ice. The antibodies used were anti-mouse CD19 Brilliant Violet 480 (catalog number 566167; BD Bioscience), anti-mouse CD11c PE-Cy7 (catalog number 117317; BioLegend), anti-mouse Ly-6G peridinin chlorophyll protein-Cy5.5 (catalog number 127615; BioLegend), anti-mouse F4/80 Brilliant Violet 421 (catalog number 123131; BioLegend), anti-mouse CD3 PE (catalog number 100205; BioLegend), and anti-mouse CD4 allophycocyanin (APC) and anti-mouse CD8 APC-Cy7 (catalog number 100713; BioLegend). The cells were washed three times with PBS and stained with a Zombie Green Fixable viability kit (catalog number 423111; BioLegend) (1:500) for 15 min according to the manufacturer's instructions. After two extra washes with PBS-1\% BSA, the cells were fixed with paraformaldehyde (PFA). The samples were analyzed on a FACSVerse flow cytometer (BD Bioscience). The neutrophil/monocyte population and the lymphocyte populations were initially identified using forward and side scatter dimensions, and the immune subpopulations were defined as follows: macrophages, CD11 $\mathrm{C}^{+} \mathrm{F} 4 / 80^{+} \mathrm{Ly}^{-} 6 \mathrm{G}^{-}$;

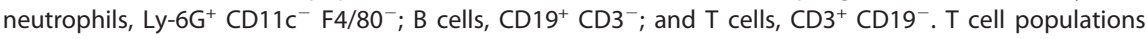
were further subdivided using CD4 and CD8 markers. Lung homogenate cytokine levels (IL-1, IL-6, IL-10, TNF- $\alpha$ ) were determined by using a Luminex magnetic bead array assay (R\&D Systems) according to the manufacturer's protocols.

Statistical methods. Statistical analyses were conducted using Prism (version 7) software (GraphPad, USA). Parametric data are presented as means, and error bars represent standard deviations (SD). Comparisons between multiple groups were conducted using analysis of variance (ANOVA) and 
the Holm-Sidak or Dunnett's posttest to compare experimental groups. Nonparametric data were analyzed using the Mann-Whitney $\mathrm{U}$ test. For the disease development model, data were analyzed using the log-rank (Mantel-Cox) test.

\section{SUPPLEMENTAL MATERIAL}

Supplemental material for this article may be found at https://doi.org/10.1128/ IAI.00846-18.

SUPPLEMENTAL FILE 1, PDF file, $0.2 \mathrm{MB}$.

\section{ACKNOWLEDGMENTS}

W.-Y.C. was supported by an MRC CASE studentship in collaboration with ImmunoBiology Ltd.; G.E. and E.R.-S. are supported by MRC grants MR/R001871/1 and $\mathrm{R} / \mathrm{N} 02687 \mathrm{X} / 1$, respectively. This work was undertaken at $\mathrm{UCLH} / \mathrm{UCL}$, which received a proportion of funding from the Department of Health's NIHR Biomedical Research Centre's funding scheme.

J.S.B. and D.G. have received fees for consultancy work from ImmunoBiology Ltd.; C.E., A.M., P.C., and C.B. are employees of ImmunoBiology Ltd.

\section{REFERENCES}

1. Said MA, Johnson HL, Nonyane BAS, Deloria-Knoll M, O'Brien KL. 2013. Estimating the burden of pneumococcal pneumonia among adults: a systematic review and meta-analysis of diagnostic techniques. PLoS One 8: e60273. https://doi.org/10.1371/journal.pone.0060273.

2. Monasta L, Ronfani L, Marchetti F, Montico M, Brumatti L, Bavcar A, Grasso D, Barbiero C, Tamburlini G. 2012. Burden of disease caused by otitis media: systematic review and global estimates. PLoS One 7:e36226. https://doi.org/10.1371/journal.pone.0036226.

3. Sørensen UB, Henrichsen J, Chen HC, Szu SC, Sorensen UBS, Henrichsen J, Chen HC, Szu SC. 1990. Covalent linkage between the capsular polysaccharide and the cell wall peptidoglycan of Streptococcus pneumoniae revealed by immunochemical methods. Microb Pathog 8:325-334. https://doi.org/10 .1016/0882-4010(90)90091-4.

4. Maruyama T, Taguchi O, Niederman MS, Morser J, Kobayashi H, Kobayashi T, D'Alessandro-Gabazza C, Nakayama S, Nishikubo K, Noguchi T, Takei Y, Gabazza EC. 2010. Efficacy of 23-valent pneumococcal vaccine in preventing pneumonia and improving survival in nursing home residents: double blind, randomised and placebo controlled trial. BMJ 340:c1004. https:// doi.org/10.1136/bmj.c1004.

5. Webster J, Theodoratou E, Nair H, Seong AC, Zgaga L, Huda T, Johnson HL, Madhi S, Rubens C, Zhang JSF, El Arifeen S, Krause R, Jacobs TA, Brooks AW, Campbell H, Rudan I. 2011. An evaluation of emerging vaccines for childhood pneumococcal pneumonia. BMC Public Health 11: S26. https://doi.org/10.1186/1471-2458-11-S3-S26.

6. Hanage WP, Finkelstein JA, Huang SS, Pelton SI, Stevenson AE, Kleinman K, Hinrichsen VL, Fraser C. 2010. Evidence that pneumococcal serotype replacement in Massachusetts following conjugate vaccination is now complete. Epidemics 2:80-84. https://doi.org/10.1016/j.epidem.2010.03 .005 .

7. Pichichero $M E$, Khan $M N, X u$ Q. 2016. Next generation protein based Streptococcus pneumoniae vaccines. Hum Vaccin Immunother 12: 194-205. https://doi.org/10.1080/21645515.2015.1052198.

8. Daniels CC, Rogers PD, Shelton CM. 2016. A review of pneumococcal vaccines: current polysaccharide vaccine recommendations and future protein antigens. J Pediatr Pharmacol Ther 21:27-35. https://doi.org/10 .5863/1551-6776-21.1.27.

9. Wilson R, Cohen JM, Reglinski M, Jose RJ, Chan WY, Marshall H, de Vogel C, Gordon S, Goldblatt D, Petersen FC, Baxendale H, Brown JS. 2017. Naturally acquired human immunity to pneumococcus is dependent on antibody to protein antigens. PLoS Pathog 13:e1006137. https://doi.org/10 .1371/journal.ppat.1006137.

10. Wilson R, Cohen JM, José RJ, de Vogel C, Baxendale H, Brown JS. 2015. Protection against Streptococcus pneumoniae lung infection after nasopharyngeal colonization requires both humoral and cellular immune responses. Mucosal Immunol 8:627-639. https://doi.org/10.1038/mi.2014.95.

11. Hvalbye BK, Aaberge IS, Løvik M, Haneberg B. 1999. Intranasal immunization with heat-inactivated Streptococcus pneumoniae protects mice against systemic pneumococcal infection. Infect Immun 67:4320-4325.
12. Malley R, Lipsitch M, Stack A, Saladino R, Fleisher G, Pelton S, Thompson C, Briles D, Anderson P. 2001. Intranasal immunization with killed unencapsulated whole cells prevents colonization and invasive disease by capsulated pneumococci. Infect Immun 69:4870-4873. https://doi.org/10 .1128/IAI.69.8.4870-4873.2001.

13. Xu X, Meng J, Wang Y, Zheng J, Wu K, Zhang X, Yin Y, Zhang Q. 2014. Serotype-independent protection against pneumococcal infections elicited by intranasal immunization with ethanol-killed pneumococcal strain, SPY1. J Microbiol 52:315-323. https://doi.org/10.1007/s12275-014 $-3583-5$.

14. Cohen JM, Chimalapati S, de Vogel C, van Belkum A, Baxendale HE, Brown JS. 2012. Contributions of capsule, lipoproteins and duration of colonisation towards the protective immunity of prior Streptococcus pneumoniae nasopharyngeal colonisation. Vaccine 30:4453-4459. https://doi.org/10 .1016/j.vaccine.2012.04.080.

15. Zügel U, Kaufmann SH. 1999. Role of heat shock proteins in protection from and pathogenesis of infectious diseases. Clin Microbiol Rev 12: 19-39. https://doi.org/10.1128/CMR.12.1.19.

16. De Nagel DC, Pierce SK. 1991. Heat shock proteins implicated in antigen processing and presentation. Semin Immunol 3:65-71.

17. Ortmann B, Androlewicz MJ, Cresswell P. 1994. MHC class I/beta 2-microglobulin complexes associate with TAP transporters before peptide binding. Nature 368:864-867. https://doi.org/10.1038/368864a0.

18. Asea A, Kraeft SK, Kurt-Jones EA, Stevenson MA, Chen LB, Finberg RW, Koo GC, Calderwood SK. 2000. HSP70 stimulates cytokine production through a CD14-dependant pathway, demonstrating its dual role as a chaperone and cytokine. Nat Med 6:435-442. https://doi.org/10.1038/74697.

19. Huang Q-Q, Sobkoviak R, Jockheck-Clark AR, Shi B, Mandelin AM, Tak PP, Haines GK, Nicchitta CV, Pope RM. 2009. Heat shock protein 96 is elevated in rheumatoid arthritis and activates macrophages primarily via TLR2 signaling. J Immunol 182:4965-4973. https://doi.org/10.4049/jimmunol.0801563.

20. Warger T, Hilf N, Rechtsteiner G, Haselmayer P, Carrick DM, Jonuleit $H$, von Landenberg P, Rammensee H-G, Nicchitta CV, Radsak MP, Schild H. 2006. Interaction of TLR2 and TLR4 ligands with the N-terminal domain of Gp96 amplifies innate and adaptive immune responses. J Biol Chem 281: 22545-22553. https://doi.org/10.1074/jbc.M502900200.

21. Jonasch E, Wood C, Tamboli P, Pagliaro LC, Tu SM, Kim J, Srivastava P, Perez C, Isakov L, Tannir N. 2008. Vaccination of metastatic renal cell carcinoma patients with autologous tumour-derived vitespen vaccine: clinical findings. Br J Cancer 98:1336-1341. https://doi.org/10.1038/sj.bjc.6604266.

22. Floto RA, MacAry PA, Boname JM, Mien TS, Kampmann B, Hair JR, Huey OS, Houben ENG, Pieters J, Day C, Oehlmann W, Singh M, Smith KGC, Lehner PJ. 2006. Dendritic cell stimulation by mycobacterial Hsp70 is mediated through CCR5. Science 314:454-458. https://doi.org/10.1126/ science.1133515.

23. Friedland JS, Shattock R, Remick DG, Griffin GE. 1993. Mycobacterial 65$\mathrm{kD}$ heat shock protein induces release of proinflammatory cytokines from human monocytic cells. Clin Exp Immunol 91:58-62. 
24. Kang HK, Lee H-Y, Lee Y-N, Jo EJ, Kim Jl, Aosai F, Yano A, Kwak J-Y, Bae YS. 2004. Toxoplasma gondii-derived heat shock protein 70 stimulates the maturation of human monocyte-derived dendritic cells. Biochem Biophys Res Commun 322:899-904. https://doi.org/10.1016/j.bbrc.2004.07.205.

25. Lima KM, Santos SA, Lima VMF, Coelho-Castelo AAM, Rodrigues JM, Silva CL. 2003. Single dose of a vaccine based on DNA encoding mycobacterial hsp65 protein plus TDM-loaded PLGA microspheres protects mice against a virulent strain of Mycobacterium tuberculosis. Gene Ther 10: 678-685. https://doi.org/10.1038/sj.gt.3301908.

26. Bonato VLD, Gonçalves EDC, Soares EG, Santos RR, Sartori A, CoelhoCastelo AAM, Silva CL. 2004. Immune regulatory effect of pHSP65 DNA therapy in pulmonary tuberculosis: activation of $\mathrm{CD}^{+}$cells, interferon- $\gamma$ recovery and reduction of lung injury. Immunology 113:130-138. https:// doi.org/10.1111/j.1365-2567.2004.01931.x.

27. Chionh YT, Arulmuruganar A, Venditti E, Ng GZ, Han JX, Entwisle C, Ang CS, Colaco CA, McNulty S, Sutton P. 2014. Heat shock protein complex vaccination induces protection against Helicobacter pylori without exogenous adjuvant. Vaccine 32:2350-2358. https://doi.org/10.1016/j.vaccine .2014.02.051.

28. Cao J, Li D, Gong Y, Yin N, Chen T, Wong CK, Xu W, Luo J, Zhang X, Lam CWK, Yin Y. 2009. Caseinolytic protease: a protein vaccine which could elicit serotype-independent protection against invasive pneumococcal infection. Clin Exp Immunol 156:52-60. https://doi.org/10.1111/j.1365 -2249.2008.03866.x.

29. Cecchini P, Entwisle C, Joachim M, Pang Y, Dalton KA, Hill S, Mcllgorm A, Chan W-Y, Brown JS, Colaco CA, Bailey CR, Clarke SW. 2015. Next generation vaccines: development of a novel Streptococcus pneumoniae multivalent protein vaccine. Bioprocess J 14:18-33.

30. Moffitt KL, Gierahn TM, Lu YJ, Gouveia P, Alderson M, Flechtner JB, Higgins DE, Malley R. 2011. TH17-based vaccine design for prevention of Streptococcus pneumoniae colonization. Cell Host Microbe 9:158-165. https://doi.org/10.1016/j.chom.2011.01.007.

31. Cohen JM, Wilson R, Shah P, Baxendale HE, Brown JS. 2013. Lack of crossprotection against invasive pneumonia caused by heterologous strains following murine Streptococcus pneumoniae nasopharyngeal colonisation despite whole cell ELISAs showing significant cross-reactive IgG. Vaccine 31:2328-2332. https://doi.org/10.1016/j.vaccine.2013.03.013.

32. Turner P, Turner C, Green N, Ashton L, Lwe E, Jankhot A, Day NP, White NJ, Nosten F, Goldblatt D. 2013. Serum antibody responses to pneumococcal colonization in the first 2 years of life: results from an SE Asian longitudinal cohort study. Clin Microbiol Infect 19:E551-E558. https://doi .org/10.1111/1469-0691.12286.

33. Ahmed MS, Derbyshire S, Flanagan B, Loh C, McCormick M, Barocchi M, Masignani V, Finn A, Zhang Q. 2014. Immune responses to pneumococcal pilus RrgA and RrgB antigens and their relationship with pneumococcal carriage in humans. J Infect 68:562-571. https://doi.org/10.1016/j.jinf .2014.01.013.

34. Xu J, Dai W, Chen B, Fan X. 2015. Mucosal immunization with PsaA protein, using chitosan as a delivery system, increases protection against acute otitis media and invasive infection by Streptococcus pneumoniae. Scand J Immunol 81:177-185. https://doi.org/10.1111/sji.12267.

35. Xin W, Li Y, Mo H, Roland KL, Curtiss R. 2009. PspA family fusion proteins delivered by attenuated Salmonella enterica serovar Typhimurium extend and enhance protection against Streptococcus pneumoniae. Infect Immun 77:4518-4528. https://doi.org/10.1128/IAI.00486-09.

36. Jomaa M, Terry S, Hale C, Jones C, Dougan G, Brown J. 2006. Immunization with the iron uptake $A B C$ transporter proteins PiaA and PiuA prevents respiratory infection with Streptococcus pneumoniae. Vaccine 24: 5133-5139. https://doi.org/10.1016/j.vaccine.2006.04.012.

37. Kirkham L-AS, Kerr AR, Douce GR, Paterson GK, Dilts DA, Liu D-F, Mitchell TJ. 2006. Construction and immunological characterization of a novel nontoxic protective pneumolysin mutant for use in future pneumococcal vaccines. Infect Immun 74:586-593. https://doi.org/10.1128/IAI.74.1.586 $-593.2006$

38. Moffitt K, Malley R. 2016. Rationale and prospects for novel pneumococcal vaccines. Hum Vaccin Immunother 12:383-392. https://doi.org/10 $.1080 / 21645515.2015 .1087625$.

39. Chan W-Y, Cohen J, Brown J. 2016. The new first-line defense: the potential of nasopharyngeal colonization in vaccine strategies. Vaccine Dev Ther 6:47-57. https://doi.org/10.2147/VDT.S89026.

40. Khan MN, Pichichero ME. 2012. Vaccine candidates PhtD and PhtE of Streptococcus pneumoniae are adhesins that elicit functional antibodies in humans. Vaccine 30:2900-2907. https://doi.org/10.1016/j.vaccine.2012 .02 .023 .
41. Glover DT, Hollingshead SK, Briles DE. 2008. Streptococcus pneumoniae surface protein PcpA elicits protection against lung infection and fatal sepsis. Infect Immun 76:2767-2776. https://doi.org/10.1128/IAI.01126-07.

42. Salha D, Szeto J, Myers L, Claus C, Sheung A, Tang M, Ljutic B, Hanwell D, Ogilvie K, Ming M, Messham B, van den Dobbelsteen G, Hopfer R, Ochs MM, Gallichan S. 2012. Neutralizing antibodies elicited by a novel detoxified pneumolysin derivative, PlyD1, provide protection against both pneumococcal infection and lung injury. Infect Immun 80:2212-2220. https://doi.org/10.1128/IAI.06348-11.

43. Tostes RO, Rodrigues TC, Da Silva JB, Schanoski AS, Oliveira MLS, Miyaji EN. 2017. Protection elicited by nasal immunization with recombinant pneumococcal surface protein A ( $\mathrm{rPspA}$ ) adjuvanted with whole-cell pertussis vaccine (WP) against co-colonization of mice with Streptococcus pneumoniae. PLoS One 12:e0170157. https://doi.org/10.1371/journal .pone.0170157.

44. Malley R, Anderson PW. 2012. Inaugural article: serotype-independent pneumococcal experimental vaccines that induce cellular as well as humoral immunity. Proc Natl Acad Sci U S A 109:3623-3627. https://doi.org/ 10.1073/pnas.1121383109.

45. Babb R, Chen A, Hirst TR, Kara EE, McColl SR, Ogunniyi AD, Paton JC, Alsharifi M. 2016. Intranasal vaccination with gamma-irradiated Streptococcus pneumoniae whole-cell vaccine provides serotype-independent protection mediated by B cells and innate IL-17 responses. Clin Sci (Lond) 130:697-710. https://doi.org/10.1042/CS20150699.

46. Tettelin $H$, Nelson KE, Paulsen IT, Eisen JA, Read TD, Peterson S, Heidelberg J, DeBoy RT, Haft DH, Dodson RJ, Durkin AS, Gwinn M, Kolonay JF, Nelson WC, Peterson JD, Umayam LA, White O, Salzberg SL, Lewis MR, Radune D, Holtzapple E, Khouri H, Wolf AM, Utterback TR, Hansen CL, McDonald LA, Feldblyum TV, Angiuoli S, Dickinson T, Hickey EK, Holt IE, Loftus BJ, Yang F, Smith HO, Venter JC, Dougherty BA, Morrison DA, Hollingshead SK, Fraser CM. 2001. Complete genome sequence of a virulent isolate of Streptococcus pneumoniae. Science 293: 498-506. https://doi.org/10.1126/science.1061217.

47. Jomaa M, Yuste J, Paton JC, Jones C, Dougan G, Brown JS. 2005. Antibodies to the iron uptake $A B C$ transporter lipoproteins PiaA and PiuA promote opsonophagocytosis of Streptococcus pneumoniae. Infect Immun 73:6852-6859. https://doi.org/10.1128/IAI.73.10.6852-6859.2005.

48. Chimalapati S, Cohen JM, Camberlein E, MacDonald N, Durmort C, Vernet T, Hermans PWM, Mitchell T, Brown JS. 2012. Effects of deletion of the Streptococcus pneumoniae lipoprotein diacylglyceryl transferase gene lgt on $A B C$ transporter function and on growth in vivo. PLoS One 7:e41393. https://doi.org/10.1371/journal.pone.0041393.

49. Schmid P, Selak S, Keller M, Luhan B, Magyarics Z, Seidel S, Schlick P, Reinisch C, Lingnau K, Nagy E, Grubeck-Loebenstein B. 2011. Th17/Th1 biased immunity to the pneumococcal proteins PcsB, StkP and PsaA in adults of different age. Vaccine 29:3982-3989. https://doi.org/10.1016/j .vaccine.2011.03.081.

50. Yuste J, Botto M, Bottoms SE, Brown JS. 2007. Serum amyloid P aids complement-mediated immunity to Streptococcus pneumoniae. PLoS Pathog 3:1208-1219. https://doi.org/10.1371/journal.ppat.0030120.

51. Park S-S, Kwon H-Y, Tran TD-H, Choi M-H, Jung S-H, Lee S, Briles DE, Rhee D-K. 2015. ClpL is a chaperone without auxiliary factors. FEBS J 282: 1352-1367. https://doi.org/10.1111/febs.13228.

52. Entwisle C, Hill S, Pang Y, Joachim M, Mcllgorm A, Colaco C, Goldblatt D, De Gorguette D'Argoeuves P, Bailey C. 2017. Safety and immunogenicity of a novel multiple antigen pneumococcal vaccine in adults: a phase 1 randomised clinical trial. Vaccine 35:7181-7186. https://doi.org/10.1016/j vaccine.2017.10.076.

53. Cohen JM, Khandavilli S, Camberlein E, Hyams C, Baxendale HE, Brown JS. 2011. Protective contributions against invasive Streptococcus pneumoniae pneumonia of antibody and Th17-cell responses to nasopharyngeal colonisation. PLoS One 6:e25558. https://doi.org/10.1371/journal.pone .0025558 .

54. Yuste J, Sen A, Truedsson L, Jönsson G, Tay LS, Hyams C, Baxendale HE, Goldblatt F, Botto M, Brown JS. 2008. Impaired opsonization with C3b and phagocytosis of Streptococcus pneumoniae in sera from subjects with defects in the classical complement pathway. Infect Immun 76: 3761-3770. https://doi.org/10.1128/IAI.00291-08.

55. Hyams C, Trzcinski K, Camberlein E, Weinberger DM, Chimalapati S, Noursadeghi M, Lipsitch M, Brown JS. 2013. Streptococcus pneumoniae capsular serotype invasiveness correlates with the degree of factor $\mathrm{H}$ binding and opsonization with $\mathrm{C} 3 \mathrm{~b} / \mathrm{iC} 3 \mathrm{~b}$. Infect Immun 81:354-363. https://doi.org/10.1128/IAI.00862-12. 
56. Hyams C, Camberlein E, Cohen JM, Bax K, Brown JS. 2010. The Streptococcus pneumoniae capsule inhibits complement activity and neutrophil phagocytosis by multiple mechanisms. Infect Immun 78:704-715. https:// doi.org/10.1128/IAI.00881-09.

57. Chimalapati S, Cohen J, Camberlein E, Durmort C, Baxendale H, de Voge C, van Belkum A, Brown JS. 2011. Infection with conditionally virulent Streptococcus pneumoniae $\Delta$ pab strains induces antibody to conserved protein antigens but does not protect against systemic infection with heterologous strains. Infect Immun 79:4965-4976. https://doi.org/10 1128/IAI.05923-11.

58. Kantsø B, Green N, Goldblatt D, Benfield T. 2015. Antibody response is more likely to pneumococcal proteins than to polysaccharide after HIVassociated invasive pneumococcal disease. J Infect Dis 212:1093-1099. https://doi.org/10.1093/infdis/jiv158.

59. Ferreira DM, Neill DR, Bangert M, Gritzfeld JF, Green N, Wright AKA, Pennington SH, Moreno LB, Moreno AT, Miyaji EN, Wright AD, Collins AM, Goldblatt D, Kadioglu A, Gordon SB. 2013. Controlled human infection and rechallenge with Streptococcus pneumoniae reveals the protective efficacy of carriage in healthy adults. Am J Respir Crit Care Med 187:855-864. https:// doi.org/10.1164/rccm.201212-22770C.

60. Goldblatt D, Ashton L, Zhang Y, Antonello J, Marchese RD. 2011. Comparison of a new multiplex binding assay versus the enzyme-linked immunosorbent assay for measurement of serotype-specific pneumococcal capsular polysaccharide IgG. Clin Vaccine Immunol 18:1744-1751. https://doi .org/10.1128/CVI.05158-11.

61. Brown JS, Hussell T, Gilliland SM, Holden DW, Paton JC, Ehrenstein MR, Walport MJ, Botto M. 2002. The classical pathway is the dominant complement pathway required for innate immunity to Streptococcus pneumoniae infection in mice. Proc Natl Acad Sci U S A 99:16969-16974. https:// doi.org/10.1073/pnas.012669199.

62. Tobian AAR, Canaday DH, Harding CV. 2004. Bacterial heat shock proteins enhance class II MHC antigen processing and presentation of chaperoned peptides to $\mathrm{CD}^{+}{ }^{+}$T cells. J Immunol 173:5130-5137. https://doi.org/10 .4049/jimmunol.173.8.5130.

63. Nanduri B, Shah P, Ramkumar M, Allen EB, Swiatlo E, Burgess SC, Lawrence ML. 2008. Quantitative analysis of Streptococcus pneumoniae TIGR4 response to in vitro iron restriction by 2-D LC ESI MS/MS. Proteomics 8:2104-2114. https://doi.org/10.1002/pmic.200701048.

64. Jayaraman GC, Penders JE, Burne RA. 1997. Transcriptional analysis of the Streptococcus mutans hrcA, grpE and dnaK genes and regulation of expression in response to heat shock and environmental acidification. Mol Microbiol 25:329-341. https://doi.org/10.1046/j.1365-2958.1997.4671835.x.

65. Bolhassani A, Rafati S. 2008. Heat-shock proteins as powerful weapons in vaccine development. Expert Rev Vaccines 7:1185-1199. https://doi.org/ 10.1586/14760584.7.8.1185.

66. Liu Y, Wang H, Zhang S, Zeng L, Xu X, Wu K, Wang W, Yin N, Song Z, Zhang $X$, Yin Y. 2014. Mucosal immunization with recombinant fusion protein DnaJ- $\Delta$ A146Ply enhances cross-protective immunity against Streptococcus pneumoniae infection in mice via interleukin 17A. Infect Immun 82:1666-1675. https://doi.org/10.1128/IAI.01391-13.

67. Cui Y, Zhang X, Gong Y, Niu S, Yin N, Yao R, Xu W, Li D, Wang H, He Y, Cao J, Yin Y. 2011. Immunization with DnaJ (hsp40) could elicit protection against nasopharyngeal colonization and invasive infection caused by different strains of Streptococcus pneumoniae. Vaccine 29:1736-44. https://doi.org/10.1016/j.vaccine.2010.12.126.
68. Khan MN, Shukla D, Bansal A, Mustoori S, Ilavazhagan G. 2009. Immunogenicity and protective efficacy of GroEL (hsp60) of Streptococcus pneumoniae against lethal infection in mice. FEMS Immunol Med Microbiol 56: 56-62. https://doi.org/10.1111/j.1574-695X.2009.00548.x.

69. Kim SN, Kim SW, Pyo SN, Rhee DK. 2001. Molecular cloning and characterization of groESL operon in Streptococcus pneumoniae. Mol Cells 11: 360-368.

70. Jensch I, Gámez G, Rothe M, Ebert S, Fulde M, Somplatzki D, Bergmann S, Petruschka L, Rohde M, Nau R, Hammerschmidt S. 2010. PavB is a surfaceexposed adhesin of Streptococcus pneumoniae contributing to nasopharyngeal colonization and airways infections. Mol Microbiol 77:22-43. https://doi.org/10.1111/j.1365-2958.2010.07189.x.

71. Basavanna S, Chimalapati S, Maqbool A, Rubbo B, Yuste J, Wilson RJ, Hosie A, Ogunniyi AD, Paton JC, Thomas G, Brown JS. 2013. The effects of methionine acquisition and synthesis on Streptococcus pneumoniae growth and virulence. PLoS One 8:e49638. https://doi.org/10.1371/ journal.pone.0049638.

72. Moffitt K, Skoberne M, Howard A, Gavrilescu LC, Gierahn T, Munzer S, Dixit B, Giannasca P, Flechtner JB, Malley R. 2014. Toll-like receptor 2-dependent protection against pneumococcal carriage by immunization with lipidated pneumococcal proteins. Infect Immun 82:2079-2086. https://doi.org/10.1128/IAI.01632-13.

73. Molzen TE, Burghout $P$, Bootsma HJ, Brandt $C T$, Van Der Gaast-De Jongh CE, Eleveld MJ, Verbeek MM, Frimodt-Møller N, Ostergaard C, Hermans PWM. 2011. Genome-wide identification of Streptococcus pneumoniae genes essential for bacterial replication during experimental meningitis. Infect Immun 79:288-297. https://doi.org/10.1128/IAI.00631-10.

74. Khandavilli S, Homer KA, Yuste J, Basavanna S, Mitchell T, Brown JS. 2008. Maturation of Streptococcus pneumoniae lipoproteins by a type II signal peptidase is required for $A B C$ transporter function and full virulence. Mol Microbiol 67:541-557. https://doi.org/10.1111/j.1365-2958.2007.06065.x.

75. Pérez-Dorado I, Galan-Bartual S, Hermoso JA. 2012. Pneumococcal surface proteins: when the whole is greater than the sum of its parts. Mol Oral Microbiol 27:221-245. https://doi.org/10.1111/j.2041-1014.2012.00655.x.

76. Whalan RH, Funnell SGP, Bowler LD, Hudson MJ, Robinson A, Dowson CG. 2005. PiuA and PiaA, iron uptake lipoproteins of Streptococcus pneumoniae, elicit serotype independent antibody responses following human pneumococcal septicaemia. FEMS Immunol Med Microbiol 43:73-80. https://doi.org/10.1016/j.femsim.2004.07.010.

77. Wang S, Li Y, Shi H, Scarpellini G, Torres-Escobar A, Roland KL, Curtiss R. 2010. Immune responses to recombinant pneumococcal PsaA antigen delivered by a live attenuated Salmonella vaccine. Infect Immun 78: 3258-3271. https://doi.org/10.1128/IAI.00176-10.

78. Miyaji EN, Dias WO, Gamberini M, Gebara VCBC, Schenkman RPF, Wild J, Riedl P, Reimann J, Schirmbeck R, Leite LCC. 2001. PsaA (pneumococcal surface adhesin A) and PspA (pneumococcal surface protein A) DNA vaccines induce humoral and cellular immune responses against Streptococcus pneumoniae. Vaccine 20:805-812. https://doi.org/10.1016/S0264 $-410 \times(01) 00395-4$.

79. Olaya-Abril A, Jiménez-Munguía I, Gómez-Gascón L, Obando I, RodríguezOrtega MJ. 2013. Identification of potential new protein vaccine candidates through pan-surfomic analysis of pneumococcal clinical isolates from adults. PLoS One 8:e70365. https://doi.org/10.1371/journal.pone .0070365 . 